\title{
Sobre los inicios del coleccionismo y los museos de arte en la Argentina
}

\begin{abstract}
Maria Isabel Baldasarre ${ }^{1}$
RESUMEN: En la Argentina del siglo XIX, la formación de importantes colecciones privadas de arte se dio con anterioridad a la fundación de los museos. Estas colecciones - mediante donaciones o legados - fueron la base de los museos de arte del país y contribuyeron a lo largo de su historia al crecimiento de sus patrimonios condicionando directamente el perfil de sus acervos.

Este artículo indaga sobre el inicio de la práctica del coleccionismo de arte en la Argentina, reconstruyendo algunas de las selecciones y mecanismos utilizados por los coleccionistas a la hora de ejercer sus juicios de gusto para armar sus conjuntos de obras. Este proceso se estudia en relación con la creación y crecimiento del primer y más importante museo de arte del país, el Museo Nacional de Bellas Artes de Buenos Aires. Se analiza con detenimiento la labor de su mentor y primer director - Eduardo Schiaffino - y los modos en que sus opciones estéticas y los dispositivos utilizados para el crecimiento del patrimonio muchas veces se continuaron en las administraciones subsiguientes. Se examinan también los casos de algunos museos creados posteriormente en el interior del país, en los que también tuvo fuerte injerencia el coleccionismo privado, pero que desde su génesis plantearon un modelo distinto al ser altamente receptivos a las producciones de arte nacional.

PALABRAS CLAVE: Argentina. Museos. Coleccionismo de Arte.

RESUMO: Na Argentina do século XIX, a formação de importantes coleções de arte privadas foi anterior à formação dos museus. Essas coleções - mediante doações ou legados formaram a base dos museus de arte do país e, no decorrer da sua história, contribuíram para o crescimento dos patrimônios museológicos, condicionando diretamente o perfil dos seus acervos.

Este artigo investiga o início da prática do colecionismo de arte na Argentina, reconstruindo algumas das escolhas e mecanismos utilizados pelos colecionadores na hora de exercer seus juízos estéticos para montar seus conjuntos de obras. Este processo é estudado em relação à criação e crescimento do primeiro e mais importante museu de arte do país, o Museu Nacional de Belas Artes de Buenos Aires. Analisa-se em detalhes o trabalho de seu mentor e primeiro diretor, Eduardo Schiaffino, e as maneiras como suas opções estéticas, e os dispositivos
\end{abstract}

1 CONICET- Instituto de Teoría e Historia del Arte "Julio E. Payro", Universidad de Buenos Aires - Argentina, e-mail: marisabalda@fibertel. com.ar 
utilizados para o aumento do patrimônio, muitas vezes prosseguiram nas administrações subseqüentes. São examinados, também, os casos de alguns museus criados posteriormente no interior do país, onde o colecionismo privado também teve forte ingerência, mas que, desde sua gênese, propuseram um modelo distinto, sendo altamente receptivos às produções da arte nacional.

PALAVRAS-CHAVE: Argentina. Museus. Colecionismo de Arte.

ABSTRACT: In nineteenth-century Argentina, the formation of important private art collections was prior to the foundation of museums. Donated or bequeathed, these collections were the basis of the country's art museums and have contributed in the course of history to the development and profile of their patrimonies. This paper examines the establishment of art collecting practice in Argentina. It takes into account some of the selections, mechanisms and judgments exercised by art collectors when forming their collections. This process is considered in relation to the creation and growth of the country's first and most important art museum: the Buenos Aires National Fine Arts Museum. The role of its first director and mentor - Eduardo Schiaffino - is thoroughly analyzed, as is the persistence, in the subsequent administrations, of his esthetic choices and mechanisms for enlarging the patrimony. We also consider the case of some museums created inland. Although private art collecting has also exerted a strong influence in their formation, these institutions proposed a different model, as they were highly receptive to national art.

KEYWORDS: Argentina. Museums. Art Collecting.

Explorar la génesis del coleccionismo de arte en los distintos casos nacionales permite analizar las relaciones que este consumo privado estableció con el surgimiento de instituciones públicas. Es decir, echar luz sobre la incidencia que este coleccionismo - generalmente de origen privado e individual - pudo haber tenido sobre la constitución de los museos nacionales o regionales de artes plásticas, museos que en el caso de muchas naciones sudamericanas como la Argentina, Chile o Perú, se fundaron tardíamente hacia fines del siglo XIX o incluso avanzado el siglo XX, con posterioridad a la constitución de nutridas colecciones privadas. A su vez, la débil institucionalidad del campo decimonónico en torno a la organización sostenida de salones y exposiciones hizo que estos países carecieran de espacios de alta visibilidad, disponibilidad y accesibilidad para la producción de sus artistas nacionales, provocando entonces que el ingreso continuado de arte realizado en el país también se produjera tardíamente.

Frente a la coyuntura europea, donde el coleccionista decimonónico puede emular o impugnar el canon artístico propuesto por los enormes museos de arte formados a partir de la estatización de las colecciones reales, resulta pertinente pensar cómo operó la inexistencia de esta tradición en las naciones sudamericanas y en qué medida el coleccionismo privado contribuyó o no a forjarla.

En el caso particular de la Argentina del siglo XIX, el desarrollo de las artes plásticas siempre fue a la zaga de otros "progresos" no sólo económicos sino también culturales. Es decir, para los ojos de la época las bellas artes eran un estadio superior al que debía aspirarse sólo cuándo hubiesen sido completamente satisfechas las necesidades de la vida material. 
Así, en 1894, varios concejales de la ciudad de Buenos Aires médicos, notarios e industriales renombrados - desestimaron el proyecto presentado por el entonces intendente Federico Pinedo de creación de un Museo Municipal de Bellas Artes (el primero en su género) al sostener - según las palabras de un concejal - que era un proyecto "inútil y perjudicial" en una sociedad que no había desarrollado "el sentimiento artístico necesario para apreciar las obras de arte" ${ }^{2}$. Pocos años habían pasado de la crisis bursátil de 1890, y la situación deficitaria de las finanzas del Estado a mediados de la década justificaba abstenerse de todo gasto innecesario. Evidentemente, las bellas artes no eran, para el proyecto de estos hombres liberales, un imperativo urgente.

A su vez frente a las otras esferas de la cultura, las artes plásticas aparecen siempre rezagadas. En los periódicos y revistas que proliferaron en la Argentina del siglo XIX, siempre es mucho mayor el espacio dedicado a la crónica y crítica teatral, por ejemplo, que el consagrado a las artes plásticas. El hecho se explicaba en la intensa temporada lírico-dramática con que contaba Buenos Aires para esos años que, con su extensa oferta de ópera, zarzuela, sainete, comedia y dramas en español, francés e italiano, atraía a públicos de diverso estrato social.

Asimismo, desde el ámbito institucional, otros proyectos museísticos contaron con más fomento durante el período considerado. Por ejemplo, las colecciones arqueológicas y antropológicas donadas por Francisco Moreno en 1877 al Gobierno de la Provincia de Buenos Aires dieron inmediato origen al Museo Antropológico y Arqueológico abierto al año siguiente en el cuarto piso del Teatro Colón. Años después, tras la transformación de Buenos Aires en ciudad capital, esas mismas colecciones fueron la base del Museo de La Plata. Inaugurado en 1890, este "museo monumento" estableció un patrón, no sólo local sino también continental de lo que debía ser un museo moderno de ciencias naturales.

Por otra parte, el contexto de la crisis económica no impidió que, por ejemplo, el Museo Histórico Nacional fuese fundado en 1889, a iniciativa del historiador Adolfo P. Carranza, e inaugurado en 1891. Sin encontrar una sede definitiva hasta fines de la última década del siglo, el museo reunió un importante conjunto de piezas históricas gracias a las intensas campañas de Carranza, en las que solicitaba objetos a los descendientes de los protagonistas de la Revolución de Mayo y las guerras de la Independencia, así como recolectaba otros dispersos por las distintas sedes gubernamentales. Sin dudas, la injerencia de los principales políticos e intelectuales del momento, entre otros los ex-presidentes Bartolomé Mitre y Julio A. Roca, y los escritores Ernesto Quesada y Carlos Guido Spano, todos integrantes de la comisión organizadora del museo, favoreció el desarrollo de este proyecto que nació también, como lo haría el Museo Nacional de Bellas Artes (MNBA), por el deseo de un puñado de hombres aquí interesados por la guarda de los testimonios históricos ${ }^{3}$.

A su vez, ya desde mediados del siglo existía la Asociación de Amigos de la Historia Natural del Plata, entidad particular que nucleaba a varios coleccionistas de numismática, objetos históricos y también artísticos, aunque la
2. Cf. La Prensa, Buenos Aires, 22 de mayo de 1894. Uno de los más fuertes defensores de este proyecto fue Eduardo Schiaffino; cf. su alegato reproducido en La pintura y la escultura en la Argentina (1783-1894). Buenos Aires: Ediciones del Autor, 1933, p. 349351.

3.Véase:AAVV, 1997. 
4.TRELLES, Manuel Ricardo.Memoria presentada a la Asociación de Ami gos de la Historia Natural del Plata, sobre el estado del Museo y demás relativos a la institución por el Secretario de la misma, D.Manuel Ricar do Trelles. Buenos Aires Impr. El Orden, 1856, p. 24.

5. Cf. MALOSETTI, 2001.

6. Cf. PASTOR OBLIGADO. La tertulia Guerri co: tradiciones argenti nas. Barcelona: Montaner y Simon, 1903, p. 348. mayor parte de sus obras de arte habían sido adquiridas no en función de los artistas realizadores sino por la temática representada, al tratarse de personajes o episodios clave para la historia nacional. Del mismo modo, el Museo Público de Buenos Aires, fundado en 1812 y reorganizado en 1823, contaba con algunas obras de arte pero éstas se exhibían indiferenciadas entre el resto de los objetos. En la memoria del museo, presentada en 1856, el coleccionista Manuel Ricardo Trelles realizaba la siguiente valoración de estas piezas: "aunque en su mayor parte no tienen mérito artístico, deben sin embargo conservarse como monumentos históricos" ${ }^{\prime 4}$.

Fundada en 1876, la Sociedad Estímulo de Bellas Artes fue la primera asociación orgánica de artistas con que contó la Argentina ${ }^{5}$. Sin embargo, si esta formación fue en gran parte responsable de la institución de la enseñanza artística - en 1905 su escuela de dibujo y pintura es la base sobre la que se instituye la Academia Nacional de Bellas Artes -, la Sociedad no produjo paralelamente la creación de un museo de bellas artes por más que la organización de una exposición permanente figuró entre sus primeros objetivos.

Mucho tuvo que ver la inestable economía del organismo, que dependía de un apoyo gubernamental fluctuante en su adjudicación de fondos y en mayor medida del también inestable aporte privado. Sin embargo, uno de los principales animadores de la Sociedad, el entonces joven estudiante de arte Eduardo Schiaffino, dos décadas después será el principal responsable de concretar la apertura del MNBA.

Hacia un coleccionismo privado de obras de arte

Durante estas décadas se forman en el país las primeras colecciones de arte originadas en el afán privado. Entre estos primeros coleccionistas debe destacarse como pionero Manuel José de Guerrico (1800-1876). Exiliado en París por razones políticas hacia la tercera década del siglo, será allí donde comience a comprar obras de arte, retornando al país en 1848 con un grupo notable de cuadros. Es importante dimensionar lo inédita que era esta práctica en la Buenos Aires de ese momento. Durante los tiempos posindependentistas las casas porteñas conservaron mucha de la austeridad que caracterizó a la etapa colonial. Hasta ese momento las obras de arte colgadas en los interiores estaban específicamente vinculadas con el culto religioso, tratándose mayormente de imágenes de cristos, vírgenes y santos. No era común el consumo de arte a los fines puramente estéticos y así definió el gobernador de Buenos Aires, Juan Manuel de Rosas, la llegada de Guerrico con sus cuadros tildándola de "modas de gringos"

¿Qué obras había elegido este primer coleccionista? En general se trataba de pinturas anónimas o copias de maestros del pasado, fundamentalmente italianos, pero también españoles, franceses o flamencos. Eran en su mayoría escenas bíblicas o religiosas, no faltando el paisaje y la pintura de género. Se 
incluían también en el conjunto quince telas del pintor gallego Genaro Pérez de Villaamil (Figura 1), adquiridas por el coleccionista en ocasión de la visita a su taller, que se ubicaba en la buhardilla de la casa ocupada por Guerrico en París.

En primer lugar, este rasgo de las autorías dudosas o débiles va a ser común durante las décadas que siguieron. Frente a la inexistencia de expertos e instituciones capaces de sancionar sobre la validez de una firma o de reconocer las marcas de estilo de un artista, va a ser común la abundancia de estas atribuciones sumamente ambiciosas donde los nombres de Rafael, Rubens o Rembrandt eran otorgados a pinturas que simplemente reproducían alguna de sus obras célebres. Esta peculiaridad contribuirá, poco a poco, a configurar una plaza receptiva a las producciones del momento, aquellas obras en las que el comprador podía estar seguro de no ser estafado en términos de calidad y precio. Al optar por el arte contemporáneo, el coleccionista confiaba en una relación directa con el artista, que consistía en concurrir a su taller, conocerlo personalmente o a través de intermediarios, o al menos solicitar un aval que certificase la autenticidad de la compra.

A su vez, los inespecíficos comercios de arte que se instalan promediando la década de 1860 en la ciudad de Buenos Aires - bazares,

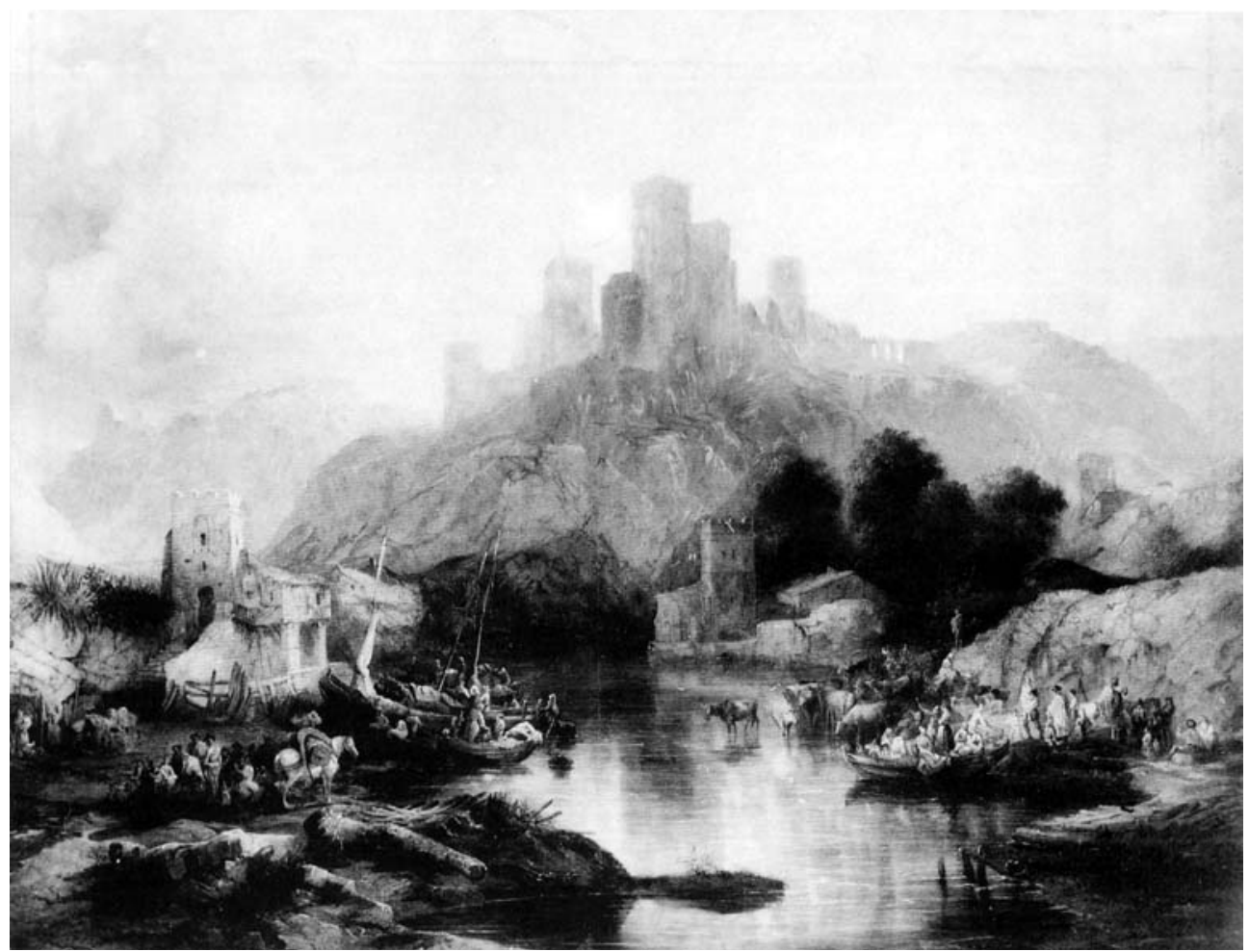

Figura 1 - Genaro Pérez de Villaamil, Castillo de Alcalá de Guadaira, 1843, óleo sobre tela, $110 \mathrm{~cm} \times 144,5 \mathrm{~cm}$. Donación Guerrico, Acervo del Museo Nacional de Bellas Artes de Buenos Aires (MNBA). 
7.AMIGO, 1998, p. 139148 pinturerías, casas de fotografía y almacenes navales donde las obras de arte se exhibían entre los más disímiles objetos ofrecidos a la venta - van a agregar a la oferta más tradicional de reproducciones en yeso y bronce de esculturas famosas, la pintura contemporánea ${ }^{7}$. Se trataba específicamente de obras que no encontraban compradores en un mercado sobresaturado por la producción de los artistas franceses, españoles e italianos que realizaban año a año las miles de piezas exhibidas en las exposiciones anuales y salones. Los Estados Nacionales adquirían los cuadros premiados, para sus museos centrales o provinciales, los burgueses contemporáneos hacían lo propio con una parte significativa de las obras, pero aún así quedaban centenares de cuadros sin dueño, que debían volver a los talleres de donde habían salido unas semanas antes.

En las últimas décadas del siglo XIX, este proceso de configuración de un mercado de arte se dio de modo gradual y oscilante en Buenos Aires, y los principales coleccionistas que se fueron constituyendo en el período debieron muchas veces acudir a la plaza europea para complementar aquellas compras factibles de realizar en la ciudad.

Este fue el caso del descendiente de italianos Adriano Rossi 11814 1893), quien efectuó un año antes de su muerte la donación fundadora de lo que sería posteriormente el MNBA. En el conjunto formado por Rossi se distinguían una treintena de escenas de género realizadas por su connacional Ignacio Manzoni (Figura 2), activo en Buenos Aires entre 1851 y 1888 . Figuraban además las obras adquiridas en el viejo continente que eran mayormente atribuciones a maestros como Moroni, Salvatore Rosa o Ribera y la eventual

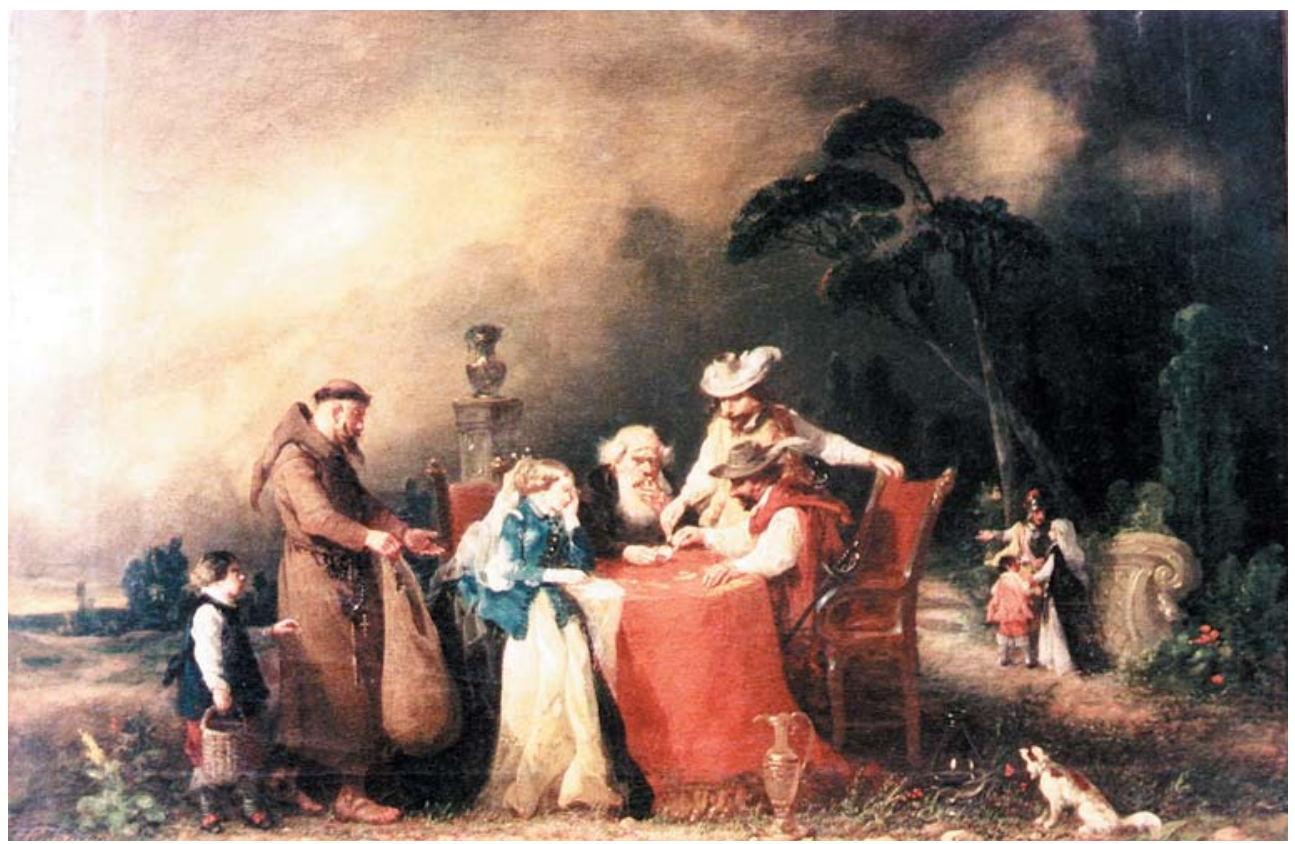

Figura 2 - Ignacio Manzoni, Abstinencia, óleo sobre tela, $62 \mathrm{~cm} \times 78 \mathrm{~cm}$. Donación Adriano Rossi, Acervo del Museo Nacional de Bellas Artes de Buenos Aires (MNBA). 
presencia de obras contemporáneas entre las que se destacan pequeños cuadros de Félix Brissot de Warville y Theódule Augustín Ribot.

Si bien Rossi tuvo una clara vocación institucional en mente a la hora de donar su conjunto de obras, antes que él otro hombre también proyectó el nacimiento del primer museo de arte a partir de la donación de su colección, en un momento en que las posibilidades concretas de su instalación eran aún más inciertas.

Fue Juan Benito Sosa ( 1839 - 1909), quien en 1877 donó a la Provincia de Buenos Aires cuarenta y ocho cuadros sobre los que aclara que han sido adquiridos con su dinero "durante un largo número de años" y que "desearía que esa colección sirviese de base para una futura galería de pintura". A diferencia de Rossi, Sosa había formado el conjunto con la oferta pictórica más limitada que ofrecía la plaza de Buenos Aires, debiendo conformarse con obras firmadas por artistas "de salón", es decir autores europeos no incluidos ni dentro de los movimientos de vanguardia del siglo XIX ni eminentes representantes de la pintura académica de entonces. Entre ellas podemos mencionar a Monje y pordiosera, del italiano Alfonso Chierici, Hidalgo español leyendo una carta, del alemán Paul Hagelstein, Paisaje (la caza del ciervo), del francés Charles Louis Desprez, Interior de bosque, del inglés Charles Davidson (Figura 3) y escenas de gallinas y aves de corral realizadas por el francés Claude Guilleminet. Como excepciones dentro de este corpus sobresalían dos pinturas de historia firmadas por los artistas contemporáneos más célebres de la colección. Ellas eran El embarque de Colón

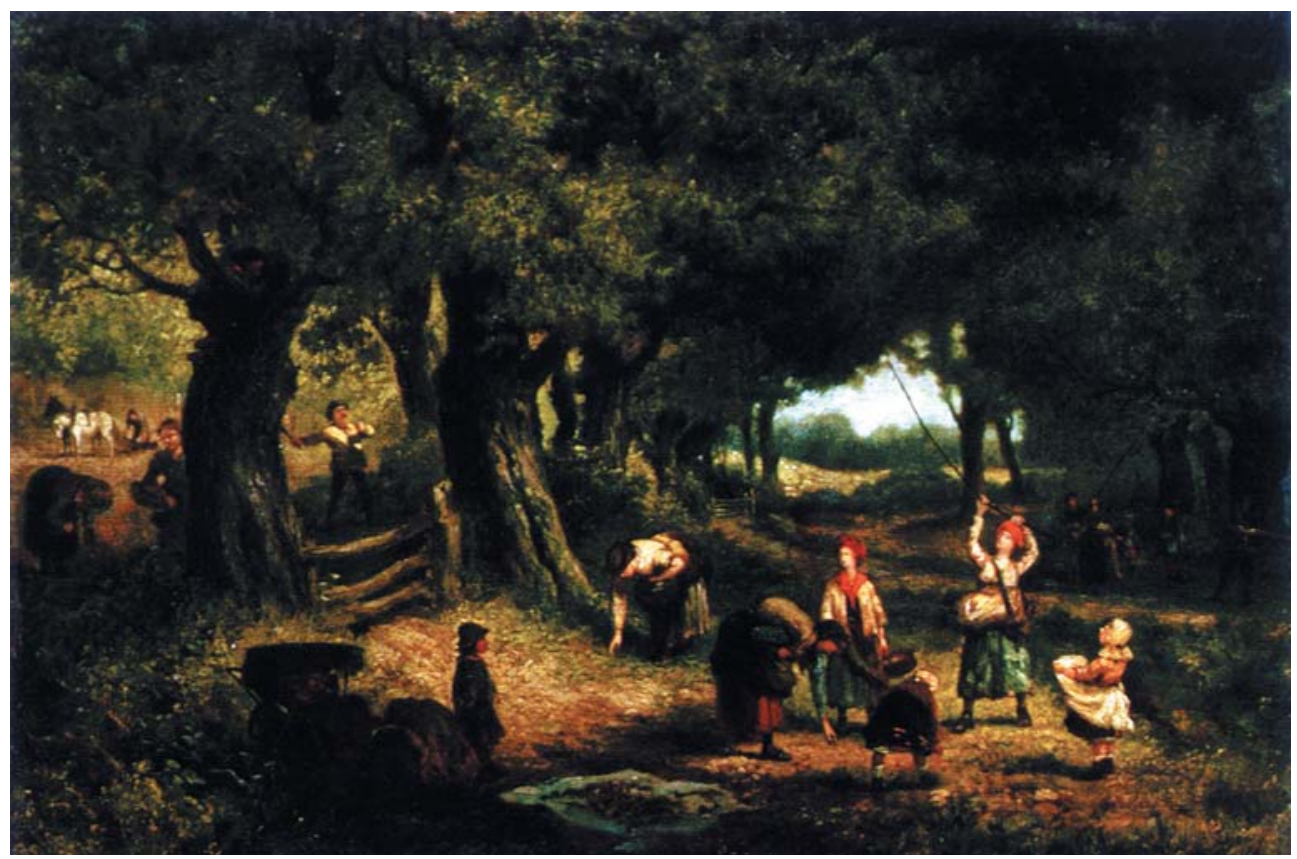

Figura 3 - Charles Davidson, Interior de bosque, óleo sobre cartón, $30 \mathrm{~cm} \times 45 \mathrm{~cm}$. Donación Juan Benito Sosa, Acervo del Museo de Bellas Artes Bonaerense (MBAB). 
8. PROYECTO Nacional de Bellas Artes para la ciudad de Buenos Aires por Juan Benito Sosa presentado al Ministerio de Instrucción Pública en noviembre de 1886. Buenos Aires; La Plata:Imprenta, litografía y encuadernación de J. Peuser, 1889. en el puerto de Palos para el descubrimiento de América, del portugués - formado en España - Ricardo Balaca y Canseco (Figura 4) y El asalto de una de las puertas de Palermo comandado por Garibaldi, del macchiaiolio Giovanni Fattori.

Por otro lado, al igual que sucedía en la colección Rossi, no faltaban aquí las telas atribuidas a grandes artistas del pasado, principalmente italianos, como Veronese, Caravaggio, Giorgione, Salvatore Rosa u holandeses como David Teniers.

Más de cuarenta años debió esperar la colección Sosa hasta encontrar el destino institucional pensado para ella. Al poco tiempo de la donación, en 1880, la ciudad de Buenos Aires se federaliza como capital, y las pinturas pasan a poder de la Provincia de Buenos Aires - a la que habían sido donadas - siendo alojadas en el recién creado Museo de La Plata. Evidentemente no contento con esta situación, Sosa redacta un proyecto en el que postula un extenso programa de apertura de un Museo Público que incluya a su vez una Escuela Nacional de Bellas Artes y una biblioteca técnica ${ }^{8}$.

La concreción del plan presentado por Sosa no se llevó a cabo, y los cuadros permanecieron en el segundo piso de una institución eminentemente pensada para albergar colecciones y producir conocimiento sobre la ciencia natural, la arqueología y la antropología americanas. En 1906, a raíz de la nacionalización de la Universidad de La Plata de quien dependía el Museo de

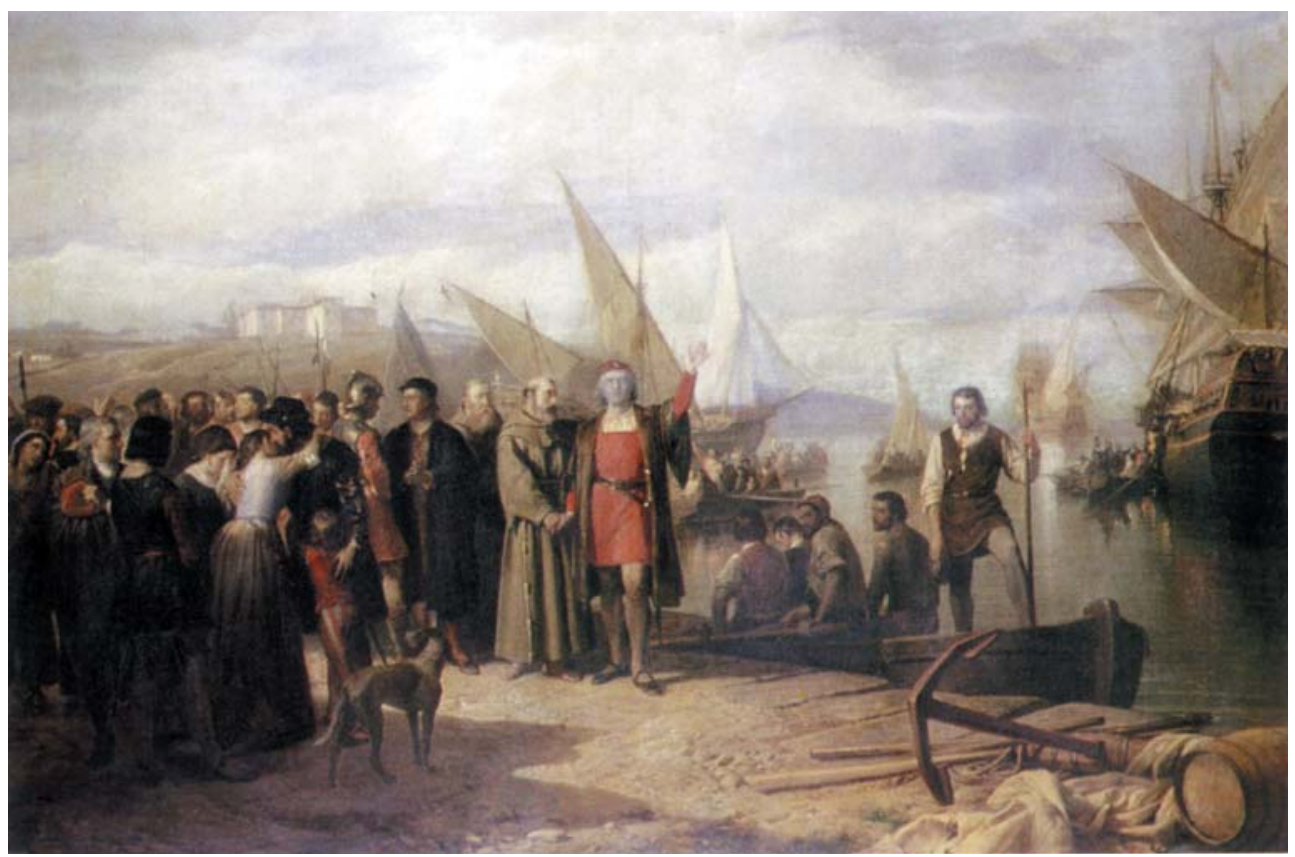

Figura 4 - Ricardo Balaca y Canseco, Cristóbal Colón en el Puerto de Palos, 1873, óleo sobre tela, $123 \mathrm{~cm} \times 185 \mathrm{~cm}$. Donación Juan Benito Sosa, Acervo del Museo de Bellas Artes Bonaerense (MBAB). 
La Plata, las obras rotaron por distintos establecimientos provinciales. Recién en 1922, reunido parcialmente el conjunto donado por Sosa, éste constituyó la colección fundadora del Museo Provincial de Bellas Artes de La Plata. Su decreto fundacional evocaba el designio del primer donante, al tiempo que justificaba la creación del organismo en la necesidad de ofrecer "al pueblo para su elevada educación, una exposición permanente de estudios artísticos en todas sus manifestaciones" proyecto decimonónico de Juan Benito Sosa, era retomado a la hora de la creación del Museo Provincial como el Leitmotiv que impulsa y justifica su creación.

El tipo de coleccionista encarnado por Sosa fue excepcional ya que, más que por deleite personal, adquirió sus obras con el propósito explícito de ofrecerlas al gobierno. La distinción social no descansó en primera instancia en la posesión y exhibición privada de las pinturas sino - desde su génesis - en el hecho de hacerlas públicas.

Si bien los otros coleccionistas contemporáneos no tuvieron tan patente esta idea de armar una colección con el fin primero y expreso de donarla al Estado, sí existió en todos ellos una gran necesidad de legitimarla, hacerla conocer y circular a partir en el dominio público. Para cumplir este objetivo los mecanismos podían ser varios: préstamo de obras para su participación en exposiciones de caridad que - mediante la exhibición de un grupo de "tesoros" privados - recaudaban dinero para fines benéficos, apertura pública de la residencia para dejar que estudiantes y aficionados a las bellas artes entraran en contacto con la colección, y circulación y difusión escrita y visual de las obras a través de las crónicas de la prensa periódica. Estos dispositivos ayudaron así a que, previamente a la instalación y apertura del MNBA, las colecciones privadas actuaran como medios privilegiados y quasi exclusivos para todo aquel que quisiera entrar en contacto directo con las obras de arte.

Paralelamente, los coleccionistas comienzan poco a poco a profesionalizarse. La práctica del viaje a Europa constituye un recurso indiscutido para enfrentar las grandes obras del arte occidental y también para apropiarse materialmente del arte contemporáneo mediante la visita a salones y talleres de artistas. Así, en las últimas décadas del siglo XIX, otras colecciones que contienen notables obras del arte producido en aquel tiempo, como las de José Prudencio de Guerrico (1837-1902) - hijo del primer coleccionista -, Aristóbulo del Valle (1 845-1896), Parmenio Piñero (1 849-1907) o Ángel Roverano (1850-1921), empiezan a formarse. El arte francés es la marca distintiva en las colecciones de Guerrico y Del Valle, mientras el español lo será en la de Parmenio Piñero. Grandes artistas de fama académica, como Jules Lefebvre (Figura 5), Ferdinand Roybet o Jean-Jacques Henner integran la colección Guerrico, en la que también se cuentan ejemplares de pintura realista y de la Escuela de 1830 - Courbet, Corot, Boudin, Daubigny, Rose Bonheur - y artistas cercanos a las búsquedas plásticas que entonces desarrollaban los impresionistas como Charles Chaplin (Figura 6), Léon Lhermitte o lgnace Fantin-Latour. Aún más moderna era la impronta 


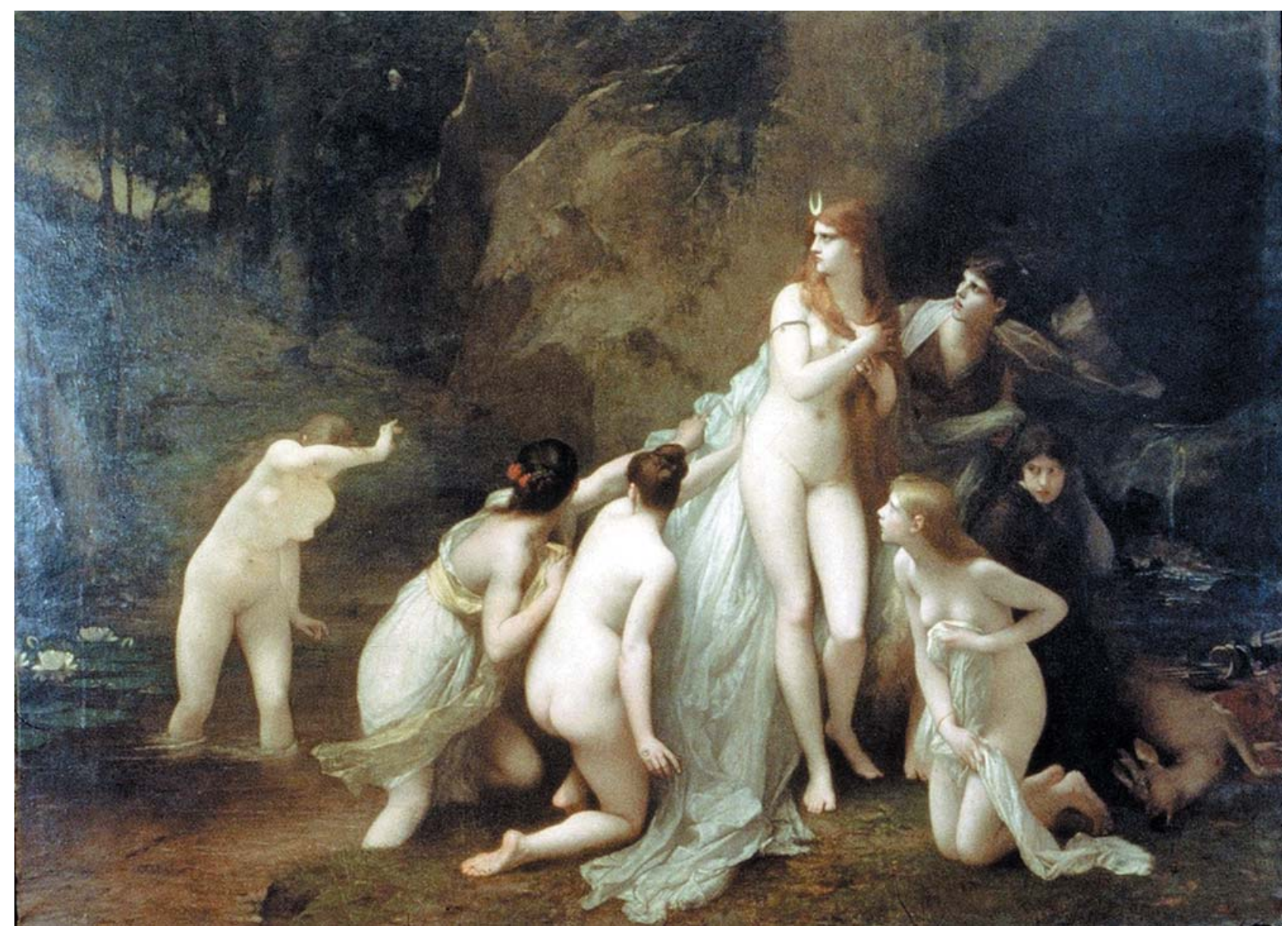

Figura 5 - Jules Lefebvre, Diana sorprendida, 1879, óleo sobre tela, $279 \mathrm{~cm} \times 371,5 \mathrm{~cm}$. Donación Guerrico, Acervo del Museo Nacional de Bellas Artes de Buenos Aires (MNBA).

10. Cf. BALDASARRE, 2005, p. 107-132. ostentada por la colección Del Valle, quien bajo la guía de su amigo personal Eduardo Schiaffino terció su gusto por el arte español e italiano para preferir las firmas de Raphael Collin, Alfred Roll, Henri Gervex e incluso Edgar Degas (Figura 7). Mientras tanto la colección de Parmenio Piñero anticipará la predilección por el arte español que caracterizó a muchos inmigrantes de ese origen en los comienzos del siglo XX. Con nombres como Mariano Fortuny, Joaquín Sorolla (Figura 8), Casto Plasencia y Francisco Domingo, el conjunto reunido por Piñero marca las preferencias de aquel consumo que será con posterioridad altamente estimulado por los marchands españoles que se instalaron en Buenos Aires y organizaron exposiciones anuales con firmas hispánicas con el propósito de ampliar el insuficiente mercado que la península ofrecía a sus artistas ${ }^{10}$. Por su parte, Ángel Roverano - quien formó su colección en los primeros años del siglo XX - repartió sus preferencias entre el arte francés, español e italiano contemporáneo. Su selección abarcaba tanto el costado más académico con 


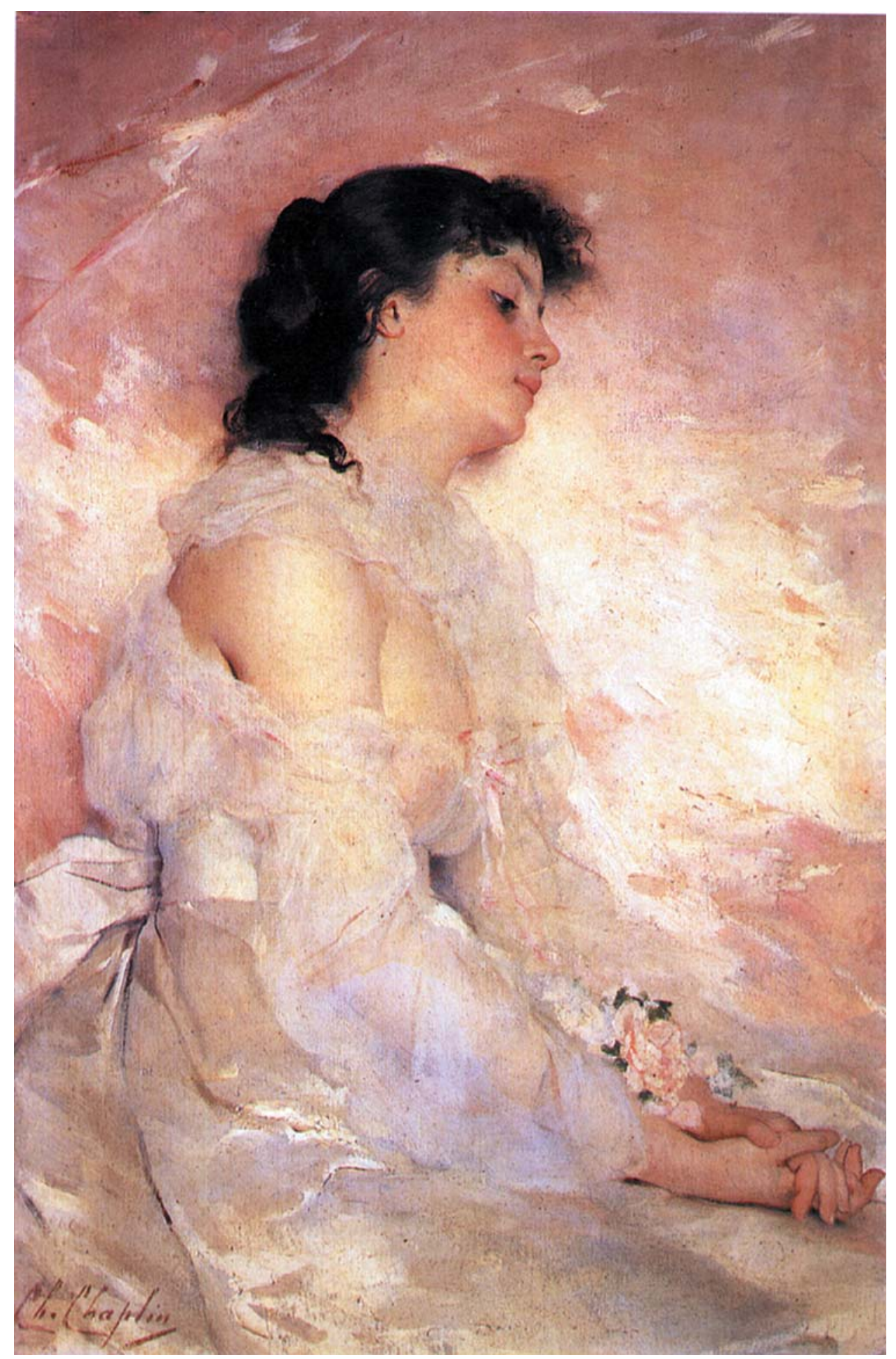

Figura 6 - Charles Chaplin, Rêverie, óleo sobre tela, 63,5cm x 42cm. Donación Guerrico, Acervo del Museo Nacional de Bellas Artes de Buenos Aires (MNBA). 
nombres como Benjamin Constant o Jean Léon Gerôme (Figura 9), pasando por la pintura del plein air - Jules Breton o Trouillebert -, hasta expresiones cercanas al impresionismo y al simbolismo como Sorolla, Santiago Rusiñol y Eugène Carrière. Al igual que sucediera una treintena de años antes con la colección formada por Sosa, también mediaron escasos años entre las compras de Roverano y su donación al Estado para su incorporación al novel MNBA. Destino directo o indirecto de la mayoría de las colecciones formadas entre el fin del siglo XIX y los comienzos de la nueva centuria, es hora de que nos ocupemos de los inicios de su historia.

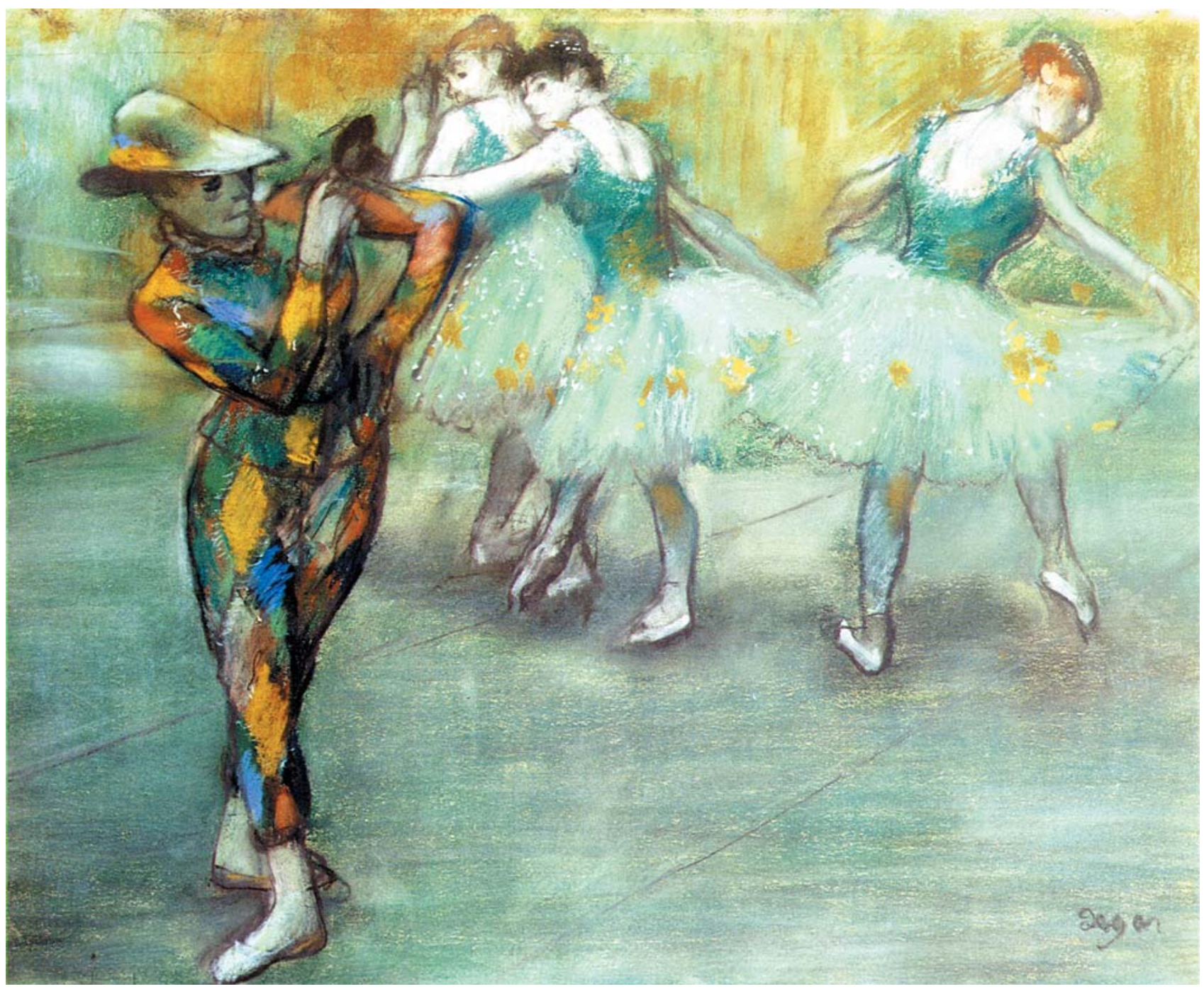

Figura 7 - Edgar Degas, Arlequín danzando, pastel sobre papel, 50cm x 63,5cm. Ex colección Aristóbulo del Valle, Acervo del Museo Nacional de Bellas Artes de Buenos Aires (MNBA). 


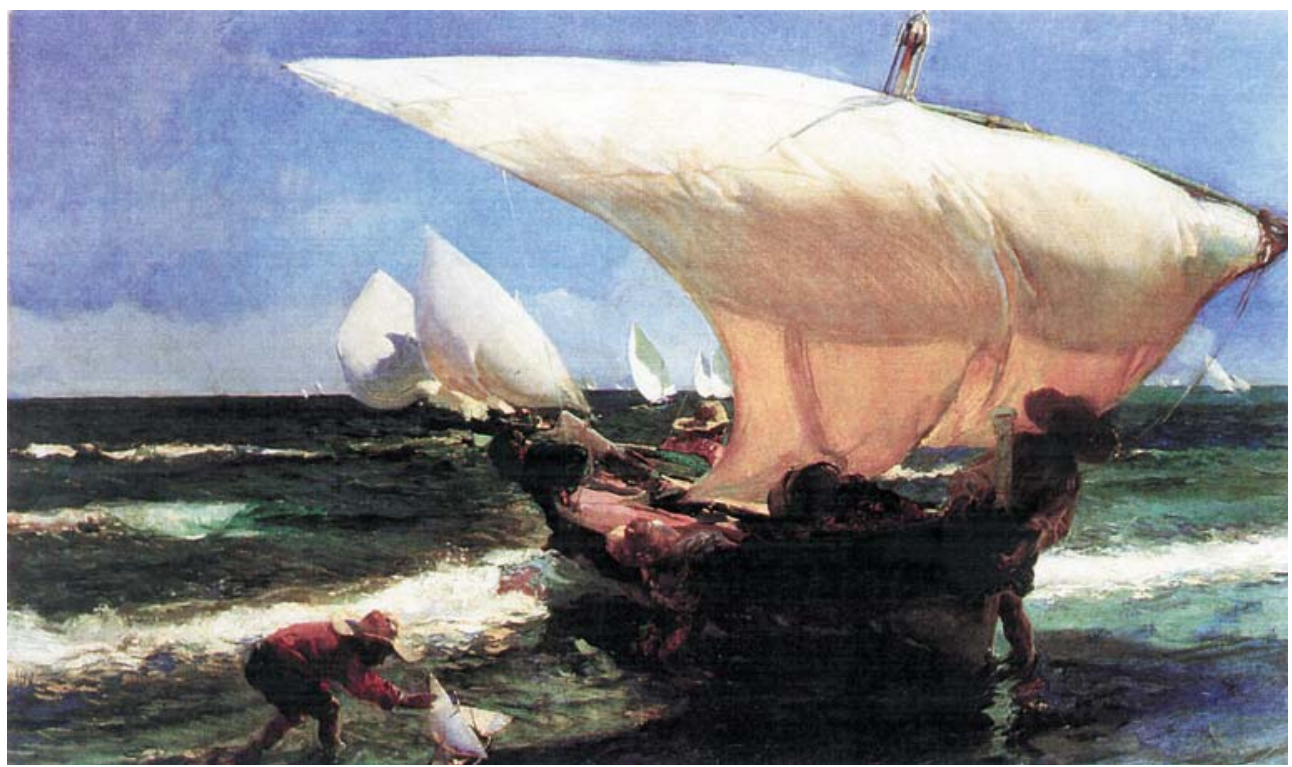

Figura 8 - Joaquín Sorolla y Bastida, En la costa de Valencia, óleo sobre tela, $57,5 \mathrm{~cm} \times 88 \mathrm{~cm}$. Legado Parmenio Piñero, Acervo del Museo Nacional de Bellas Artes de Buenos Aires (MNBA).

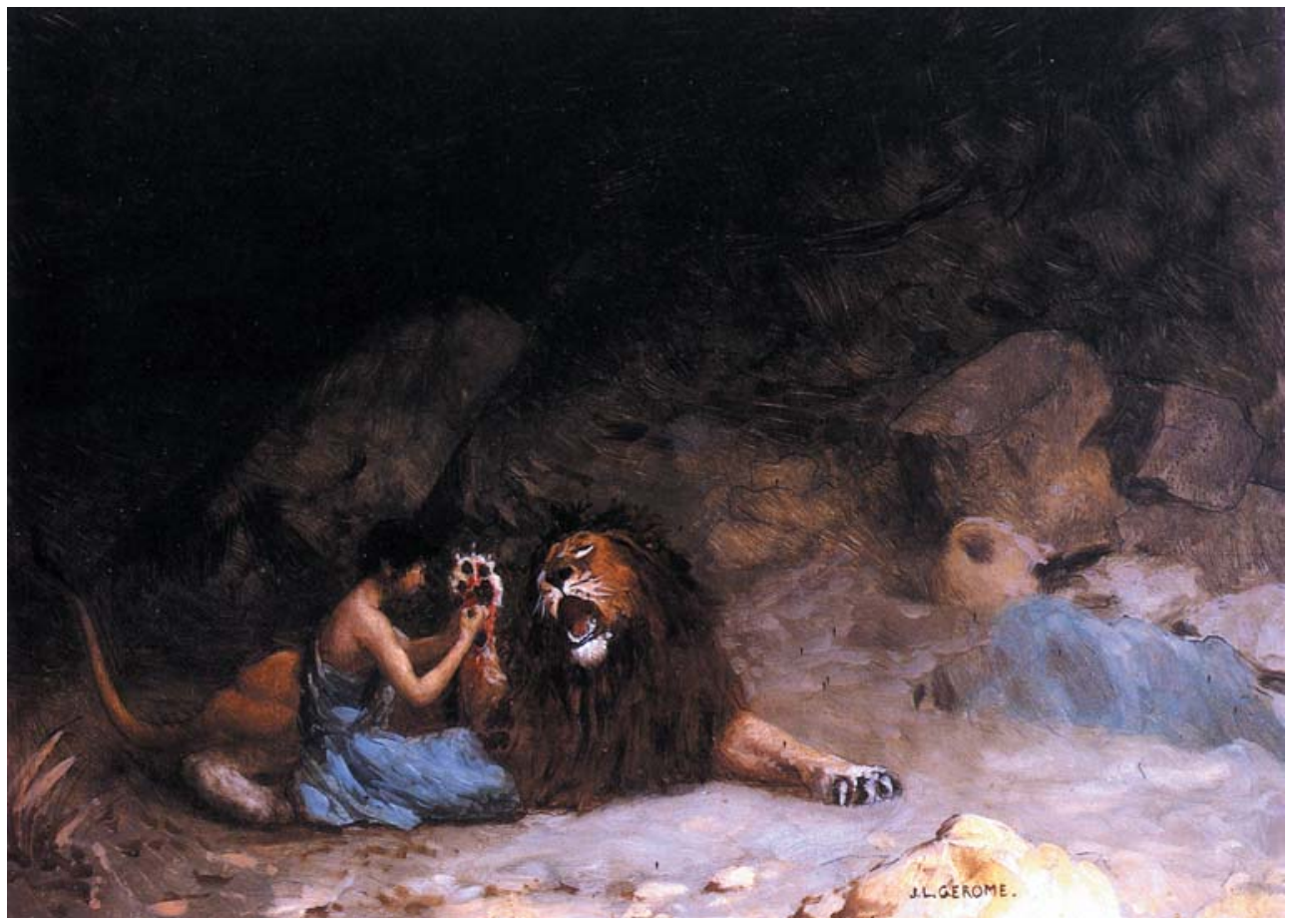

Figura 9 - Jean Léon Gérôme, Androcles, óleo sobre tela, 30cm x 40cm. Donación Ángel Roverano, Acervo del Museo Nacional de Bellas Artes de Buenos Aires (MNBA). 
11. Extraído de la Autobiografía de Eduardo Schiaffino, inédita, posterior a 1933. ARCHIVO GENERAL DE LA NACIÓN. Archivo Schiaffi no (AS-AGN).

12. Reproducido en MNBA, 1886, p. 5-7.

13. FERRY Jules; MINIS TERE DE L'INSTRUCTION PUBLIQUE ET DES BEAUX-ARTS.Rapport de la sous-commision du Conseil Supérier des arts pour la création d'un caisse des musées. 13 juin 1890. Citado en GEORGEL, 1994, p. 67.
La creación del Museo Nacional de Bellas Artes

"El presidente Roca en una visita nocturna [al museo] asombrado del incremento de las colecciones pregunta al director: ¿ Cómo han hecho Uds. esto? Esto se ha hecho con la escasa ayuda que nos han prestado los Gobiernos, calcule el Sr. Presidente lo que haríamos si se nos ayudara un poco"11. Esta es la manera en que el anciano pintor, crítico e historiador Eduardo Schiaffino (1858-1935) elige recordar sus años a cargo del naciente Museo de Bellas Artes. El autorretrato pinta a un personaje desafiante que no tiene prurito alguno en reconocer, incluso ante el Presidente de la Nación, los esfuerzos personales realizados para construir un museo que parece no importar demasiado a los ministros y gobiernos de turno. La concreción y crecimiento del MNBA fueron, más de una vez, narrados por Schiaffino como una epopeya personal, en la cual luchó y especuló de manera solitaria para otorgar al país una institución que hacía décadas debía haberse creado.

Firmado por el Presidente José Evaristo Uriburu y por el Ministro de Instrucción Antonio Bermejo, el decreto de creación del Museo Nacional de Bellas Artes, con fecha del 16 de julio de 1895, justificaba la apertura de la institución sobre tres ejes. En primer lugar, la necesidad de dotar a las obras, que tan generosamente habían sido donadas por los coleccionistas, de un lugar apropiado para su conservación y cuidado, objetivo que se encontraba estrechamente ligado con el segundo sentido otorgado al museo: el pedagógico. En tercer término figuraba el apremio por proporcionar al naciente arte nacional "de la institución oficial a la que tiene derecho"12.

Mientras que el primero de los sentidos aparecía como una obligación moral contraída con quienes habían legado sus obras con la función específica de crear un museo de pintura - los casos concretos de Adriano Rossi y José Prudencio de Guerrico, quien se había sumado con la donación de 22 obras -, las otras dos razones también constituyen claves a la hora de analizar la génesis del primer museo artístico del país. La función pedagógica, fundamental también en los emulados museos franceses del siglo XIX, condicionó sin duda las adquisiciones realizadas por la institución durante sus primeras décadas de existencia. La lección francesa parece estar tan presente en su descendiente argentino que incluso resultan adecuadas las palabras que Jules Ferry, presidente del Consejo Superior de Bellas Artes de Francia, refiere en 1890 para los museos franceses: "La importancia real de un museo no se mide más, hoy en día, en la presencia de algunas obras maestras firmadas por nombres célebres, por más raras, por más perfectas que sean, sino en su valor educativo que resulta por sobre todo de la plenitud y el encadenamiento histórico de las series" ${ }^{\prime \prime}$. A lo largo de las décadas que siguieron, el MNBA se caracterizó muchas veces por la presencia de obras que - cuestionadas por no ser las más significativas de sus autores - se incluyeron sin embargo en su patrimonio bajo la consideración de que la institución debía ser representativa e inclusiva del arte de una época. 
El tercero de los móviles sostenidos a la hora de justificar la sanción del decreto - la necesidad de dotar al arte nacional de un lugar plausible de alojar las producciones de sus hijos dilectos - se entronca fuertemente con el argumento ya esbozado de, constituido en un verdadero topos de la crítica artística finisecular, refería al atraso de las artes plásticas frente al progreso de la esfera económica e incluso frente a otras áreas del saber intelectual.

El propio Schiaffino retomaba esta argumentación en el discurso pronunciado en ocasión de la apertura del museo, un año y medio después de firmado el decreto de su creación, donde cuestionaba el énfasis puesto por el gobierno en el fomento de la educación común. En sus palabras: "A nosotros nos parece que todo está hecho cuando multiplicamos escuelas elementales en nuestro vastísimo territorio, como si el objetivo que se persigue fuera tan sólo el de dotar al mayor número de un rudimento de instrucción que coloque a millares de argentinos en aptitud de discutir lo que no saben y de opinar sobre lo que ignoran"14. Schiaffino no mide la intensidad de sus críticas frente a aquellos que creen que la Argentina no es una nación de artistas y se sienten más heridos por escribir con faltas de ortografía el nombre de un prócer que por destinar el dinero nacional a extranjeros para que esculpan las imágenes de los argentinos ilustres. Puede suponerse también, que aquí había además una crítica indirecta a la política del Ministro Bermejo bajo cuya gestión se propulsó y publicitó la construcción masiva de escuelas.

Schiaffino parangonaba el recién creado museo argentino con "más de un viejo y venerado museo provincial de Europa". Seguramente, realizaba la comparación a los fines de destacar la capacidad de la Argentina de crear, casi de la nada y apelando a la generosidad de sus habitantes, un museo equiparable a una institución con cierta tradición e historia como podría ser un museo regional decimonónico, y que esperaba en el futuro poder referirse a los museos centrales y no ya a los ejemplos periféricos.

No obstante, al momento de valorizar el nuevo proyecto, tanto Schiaffino como Bermejo, quien también expone un discurso con motivo de la inauguración, hallan su argumento más fuerte no en el goce puramente artístico sino en su potencialidad económica. Ambos coinciden en resaltar las aplicaciones del arte a la industria: "fuente de prosperidad y engrandecimiento y uno de los factores, no despreciables, de la riqueza nacional". No es casual que las defensas corran por esta vía, si tenemos en cuenta que una de las objeciones con más peso en contra de la creación del museo había sido precisamente el restar tiempo con lujos superfluos a las que se suponían las principales actividades del país: la industria y el comercio.

Más allá de apelar a estos referentes europeos, en el ideario de Schiaffino serán los museos norteamericanos los que tendrán siempre el lugar de faros a seguir por su par argentino. Repetidas veces durante su gestión refiere al Museo Metropolitano de Nueva York, a la National Gallery de Washington o al Instituto de Arte de Chicago como modelos a imitar y la insistencia se debe, sin duda, a la gran importancia que los capitales privados estadounidenses tuvieron en la formación y engrandecimiento de sus colecciones. La acción civil, según sus propias palabras "es [allí] tan frecuente, poderosa y unánime, que ha suplantado la acción oficial"15. Desalentado frente a la escasez de fondos 
16. En algunos casos, como el de la familia Guerrico, no fueron los propios coleccionistas quienes donaron la mayoría del conjunto sino sus descendientes. Sin embargo, es el mismo espíritu el que anima este gesto, en la medida que lo hicieron cumpliendo un deseo de sus antecesores y son sus nombres los que figuran como donadores

17. SCHIAFFINO, Eduardo. La orientación del arte. La Nación, Buenos Aires, 28 de diciembre de 1906.

18. Este hecho marcó sin duda el futuro de una institución que hasta hoy en día carece de una política clara de adquisiciones, básicamente por no contar con un presupuesto sostenido sobre el cual proyectar las compras en base a un guión y a un criterio museográfico rector. públicos, el director pretende mediante este ejemplo estimular a los coleccionistas y amateurs porteños a realizar una labor similar en nuestro país. Los principales museos europeos, formados a partir de la estatización de las colecciones reales, a la hora de promover el crecimiento del patrimonio no constituían modelos tan aptos como los norteamericanos. Mientras que Estados Unidos contaba con el aliciente de ser una nación "nueva", como la Argentina, y que poco a poco había demostrado su poder de asimilación de la cultura europea hasta hacerla propia.

De cómo algunas obras ingresaron al MNBA

El museo abrió sus puertas en diciembre de 1896, en los altos del Bon Marché, un gran edificio de tiendas y talleres de artistas ubicado sobre la calle Florida, la misma arteria elegante en la que se encontraban la mayor parte de los comercios de arte de la ciudad.

Las donaciones procedentes de colecciones privadas suministraron el patrimonio germinal sobre el que se cimentó el patrimonio público. Todos los coleccionistas mencionados, con excepción de Aristóbulo del Valle cuya colección ingresó por adquisición y no por donación, cedieron total o parcialmente sus posesiones para integrar el MNBA ${ }^{16}$. Más allá del gesto de filantropía que suponía el regalo de parte del patrimonio privado, todos ellos buscaron también perpetuarse en la historia de la institución figurando como donantes. Schiaffino captó certeramente la trascendencia del gesto y la importancia de promocionarlo, incluyendo ya en el primer catálogo del museo, publicado en 1896, la nómina completa de quienes habían cedido obras. Sin embargo, es necesario tener en cuenta que, si bien en el futuro ellos serían "canonizados" por participar del patrimonio original del MNBA, en el momento de su donación los coleccionistas estaban contribuyendo a una institución que recién surgía y que por tanto no era aún un órgano legitimador como lo sería años después.

Es así que estas preferencias y gustos personales nutrieron y modelaron el perfil del primer museo de artes plásticas, configurando una institución que en sus inicios, al igual que el coleccionismo privado del momento, privilegió el arte europeo contemporáneo, en desmedro de las producciones del pasado y del arte nacional. Por momentos, Schiaffino parece querer subsanar esta tendencia tal como lo demuestran algunas adquisiciones de arte antiguo y los pedidos incesantes de obras que realiza a sus amigos y colegas artistas argentinos. Sin embargo, por más que gustaba proclamar su objetividad en materia de gusto y afirmaba que en los museos del siglo XX debía haber "diversidad y anarquía de estilos"17, el primer director también puso en juego su afición individual que, en muchos aspectos, no distaba de aquella de los coleccionistas que él mismo frecuentaba, y esta predilección halló una ocasión única de ser puesta en práctica en las compras que realizó en sus viajes a Europa.

Luchando con un presupuesto escaso y discontinuo, Schiaffino debió por momentos ejecutar verdaderas "proezas" a fin de engrandecer el acervo del museo ${ }^{18}$, las que hallaron en la prensa a un órgano funcional para difundir 


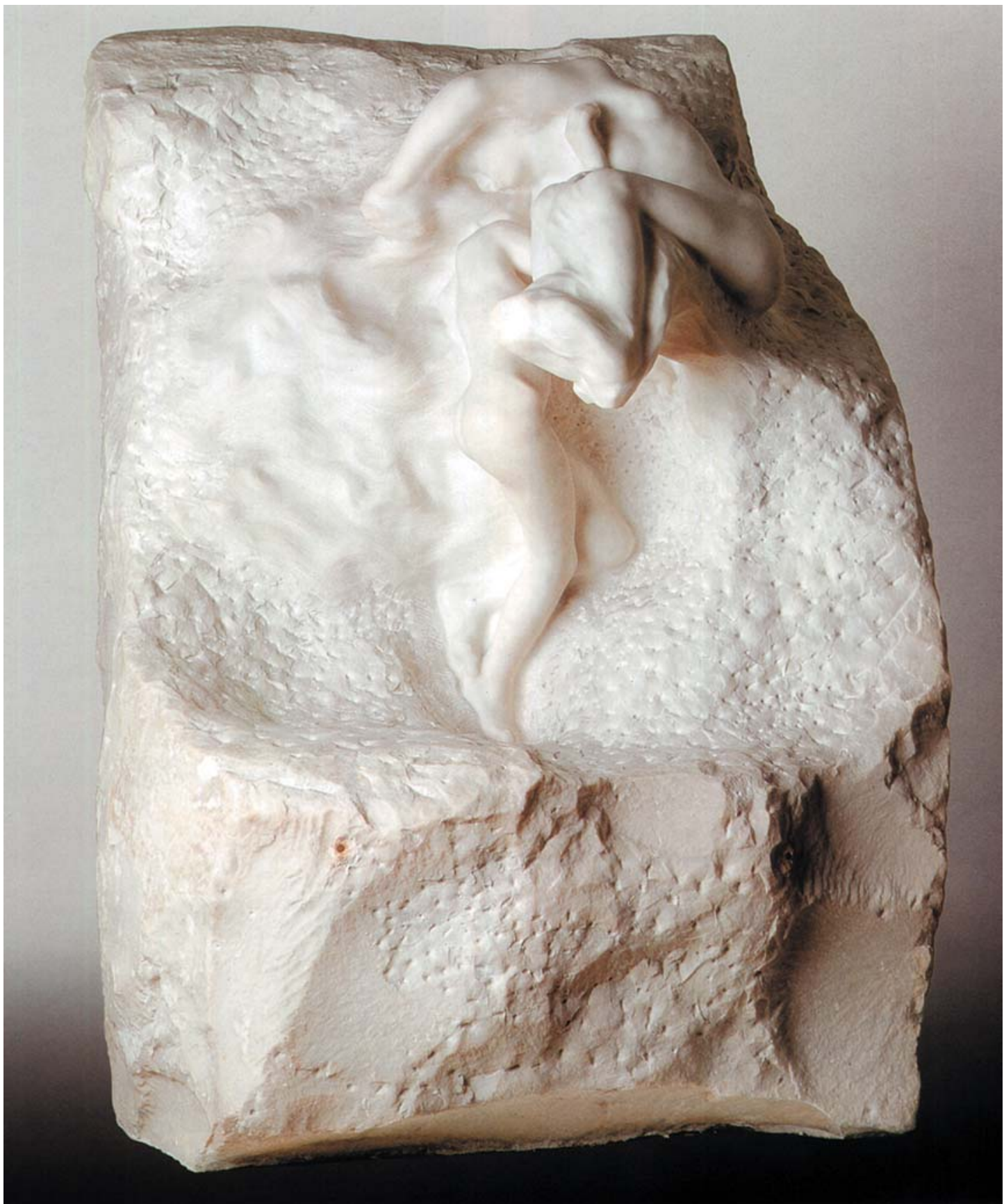

Figura 10 - Auguste Rodin, La tierra y la luna, 1904, mármol, h.: 133,5cm. Adquirido por Eduardo Schiaffino en 1906, Acervo del Museo Nacional de Bellas Artes de Buenos Aires (MNBA). 
19. La Razón, Buenos Aires, 4 de junio de 1905 ; Caras y Caretas, Buenos Aires, 6 de mayo de 1905; y La Nación, Buenos Aires, 3 de agosto de 1905 . su cruzada. A fin de llenar las paredes del Bon Marché, Schiaffino recurrió también a la reunión de las obras dispersas por reparticiones nacionales, debiendo muchas veces vencer obstáculos burocráticos que no facilitaron el inmediato ensanchamiento del acervo.

Los problemas también surgieron al momento de adquirir obras de los propios artistas o de particulares. Con la promesa de los pagos a crédito, años después de concretadas las compras encontramos a los acreedores exigiendo lo adeudado. Este fue el caso del pintor Jean François Rafaëlli, a quien para 1909 todavía se le debía parte del importe de los cuadros comprados por Schiaffino en su taller tres años antes. Algo similar ocurría con la adquisición de la colección de Aristóbulo del Valle. La relación personal sostenida por Schiaffino y el coleccionista facilitaba seguramente las condiciones de compra. No obstante, la amistad no era suficiente para garantizar el pago efectivo de las cuotas, siendo más de dos años los que deberá esperar Julia Tejedor, viuda de del Valle, para, reclamos mediante, recibir el pago total de la operación gestionada en enero de 1901.

Dos momentos clave de ingreso de obras al museo fueron los viajes a Europa concretados por Schiaffino en 1905 y 1906. Ambas travesías presentaron oportunidades excepcionales en las que el primer director pudo hacer libre uso de sus decisiones y utilizar un presupuesto destinado específicamente al engrandecimiento del MNBA. A partir de 1907, estas facultades se verían cercenadas por la reorganización de la Comisión Nacional de Bellas Artes (CNBA), organismo que pasaba a regir el MNBA y tenía entre otras atribuciones la supervisión de todas las compras artísticas. Entre las piezas seleccionadas en 1905, la prensa destacó las obras antiguas de Van Oost, Van Thulden y Adriaen Brauwer y varias contemporáneas firmadas por nombres franceses, siendo Nonchalance, de Raphael Collin, y los bocetos regalados por Albert Besnard las más alabadas en las crónicas periodísticas ${ }^{19}$.

Al año siguiente Schiaffino realizó la compra más significativa de todas las efectuadas en los quince años de su dirección. Para reforzar el valor de sus adquisiciones, Schiaffino citaba los cumplidos que éstas suscitaron en el Conservador del Museo del Luxemburgo. La alusión a miembros de prestigiosas instituciones, asombrados por las acertadas y económicas elecciones del director sudamericano, fue otro de los dispositivos recurrentes para avalar sus transacciones europeas.

En este contexto, Schiaffino concretó importantes compras de obras de arte del pasado, con autores como Murillo, Ribera, Tiziano, Goya y Pacheco, y también encargó inmensas esculturas a coetáneos españoles como Miguel Blay y Agustín Querol. Sin embargo, su apuesta más fuerte se había dirigido al arte francés de aquel momento, privilegiando la escuela "moderna". Entre los cuadros llegados a Buenos Aires, sobresalían las firmas de Boudin, Renoir, Cottet, Ribot, Raffaëlli, Blanche, Carrière, Forain, Le Sidaner, Henner, Ménard y FantinLatour, y el imponente mármol original La tierra y la luna de Auguste Rodin (Figura 10). La mayoría de los cuadros poseía como carta de presentación el haber figurado en el último salón de mayo.

Las adquisiciones realizadas representan para él ejemplos paradigmáticos de las nuevas escuelas artísticas así como la posibilidad concreta de introducir la pintura moderna en el museo argentino. Su opción por el arte de su tiempo es clara, y así lo afirma en las declaraciones a la prensa: "El pueblo 
prefiere instintivamente la pintura contemporánea porque algo reconoce a lo que está vinculado: el arte del pasado es para él lengua muerta" 20

Sin embargo, y cuestionando esta imagen que Schiaffino gustó erigir de sí mismo como un sagaz "descubridor" de obras de ocasión, sabemos que se pagó por estas pinturas los precios usuales que cotizaban entonces, pudiendo, de haberlo querido, optar por cuadros realistas o impresionistas realizados por Daumier, Daubigny, Pissarro, Monet o Sisley ${ }^{21}$. Schiaffino se atuvo a los precios que la ley de la oferta y la demanda marcaba en los remates parisinos. La escasez de impresionismo y realismo se debe entonces a una elección precisa, justificándose en su fuerte atracción hacia el simbolismo y sus epígonos, vertiente que lo cautivaba desde su juventud ${ }^{22}$.

Estas dos campañas de adquisiciones que Schiaffino realiza en Europa no tuvieron continuidad en los años que prosiguieron. Las incorporaciones se fueron dando de modo mucho más errático, por las eventuales donaciones, o las compras que entonces se efectuaron aprovechando del mercado más formalizado que comenzaba a exhibir la propia ciudad de Buenos Aires. No obstante, y si bien Schiaffino debía ahora dar cuenta de sus decisiones a las autoridades de la CNBA, gran parte de sus predilecciones en materia de arte moderno persistieron vigentes. Por ejemplo en 1908 y 1909, el museo aprovechó las grandes exposiciones de arte francés realizadas en la sede del Pabellón Argentino ${ }^{23}$, para proveerse obras, siendo favorecidas las firmas de Joseph Bail, Jules Adler, Henri Martin y el español Ramón Casas (Figura 111. Asimismo, la Exposición Internacional de Arte del Centenario - celebrada en 1910 para conmemorar los cien años de la Revolución de Mayo - constituyó una ocasión más que propicia para el ingreso de obras a la institución. El museo contó excepcionalmente con un presupuesto importante provisto por el Senado y la Municipalidad. En la misma tónica de lo que venimos observando, el arte francés fue el gran favorito y al cual se destinó gran parte del presupuesto con obras de Jacques Blanche, Caro-Delvaille, Guirand de Scévola, Auguste Rodin y Claude Monet (Figura 12) entre muchas otras. El segundo lugar fue para la escuela española, donde Hermenegildo Anglada Camarasa e Ignacio Zuloaga (Figura 13) también lograron ubicar sus obras a precios más que convenientes. El arte nacional tuvo un lugar menor, con importes sensiblemente inferiores a los pagados por las producciones internacionales.

Esta subvaloración había primado también durante la gestión de Schiaffino, quien privilegió la presencia de sus amigos artistas, aquellos que lo habían acompañado desde los talleres de la Sociedad Estímulo en el último cuarto del siglo XIX, muchas veces a costa de una perceptible reducción de los valores monetarios de sus obras. Así en las adquisiciones que hace a sus colegas, Eduardo Sívori, Ernesto de la Cárcova (Figura 14), Augusto Ballerini o Lucio Correa Morales, solicita frecuentemente ser favorecido en los precios bajo el argumento de la importancia que significaba el figurar con obra en el dominio del MNBA. De algún modo, el museo acataba los precios de mercado que entonces se pagaban por el arte producido en el país, aquellos que levantaban constantes quejas y reclamos por parte de los propios artistas. Estas producciones estaban excluidas de la mayoría de las colecciones privadas, porque
20. SCHIAFFINO, Eduardo. El crepúsculo de los ídolos. La Nación, Buenos Aires, 20 de mayo de 1909.

21. Cf. MUSEO NACIONAL DE BELLAS ARTES. VI Ensanche: Adquisiciones de 1906 efectuadas en Europa por la Dirección: catálogo. Obras expuestas al público en 1908,AS-AGN. En los márgenes de este catálogo se consigna el precio de gran parte de las obras adquiridas.

22. Cf. TELESCA; BURUCÚA,1989-1991,p.65-73.

23. Edificio que había sido construido para alojar el envío argentino a la Exposición Universal de París en 1889 y que fue reconstruido en la Plaza San Martín en Buenos Aires.A partir de 1909 y hasta 1932 fue la sede del MNBA. 


\section{COMISIÓN NACIONAL DE BELLAS ARTES} COMPRA DE TUADROS

Como lo anunciamos en el número anterior, la comisión nacional de Bellas Artes, adquirió en exposiciones clausuradas
Los euadros que reproducimos son los adquiridos, $y$ si bien, por una parte apiaudimos á la comisión de Bellas Ar-

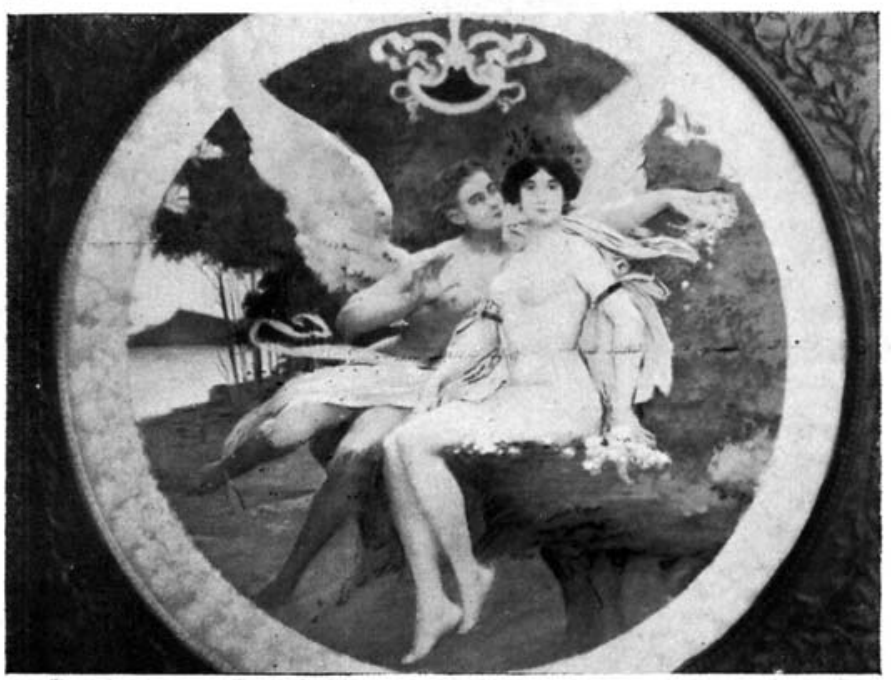

GUILl.AU ME DUBUFE. - "Eros y Psiquis".

no ha mucho tiempo, algunas obras destinadas á enriquecer nuestro museo de Bellas Artes.

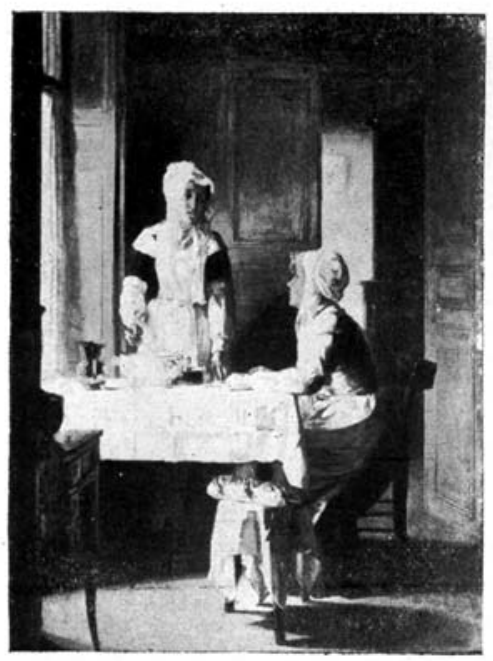

JOSEPH BAIL. - Le Repas de servantes. . tes. por esa adquisición, debemos lamentar también que se haya dejado entrever la parcialidad en la valuación de esos

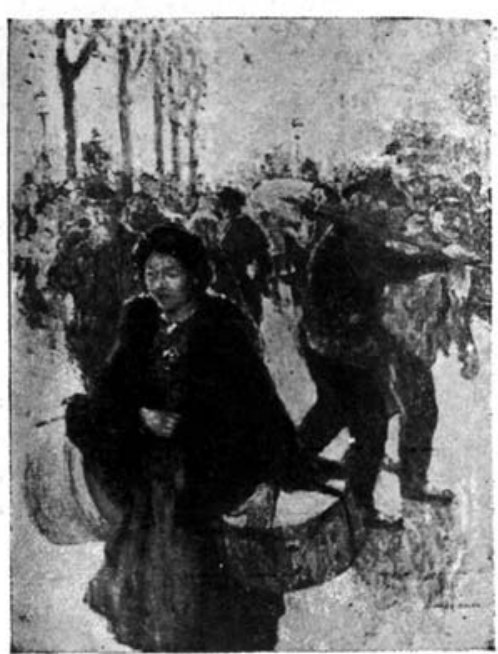

JULES ADLER. - Les§Boulevards.

Figura 11 - Comisión Nacional de Bellas Artes. Compra de cuadros. Athinae, Buenos Aires, año 1, n. 2, octubre de 1908. 


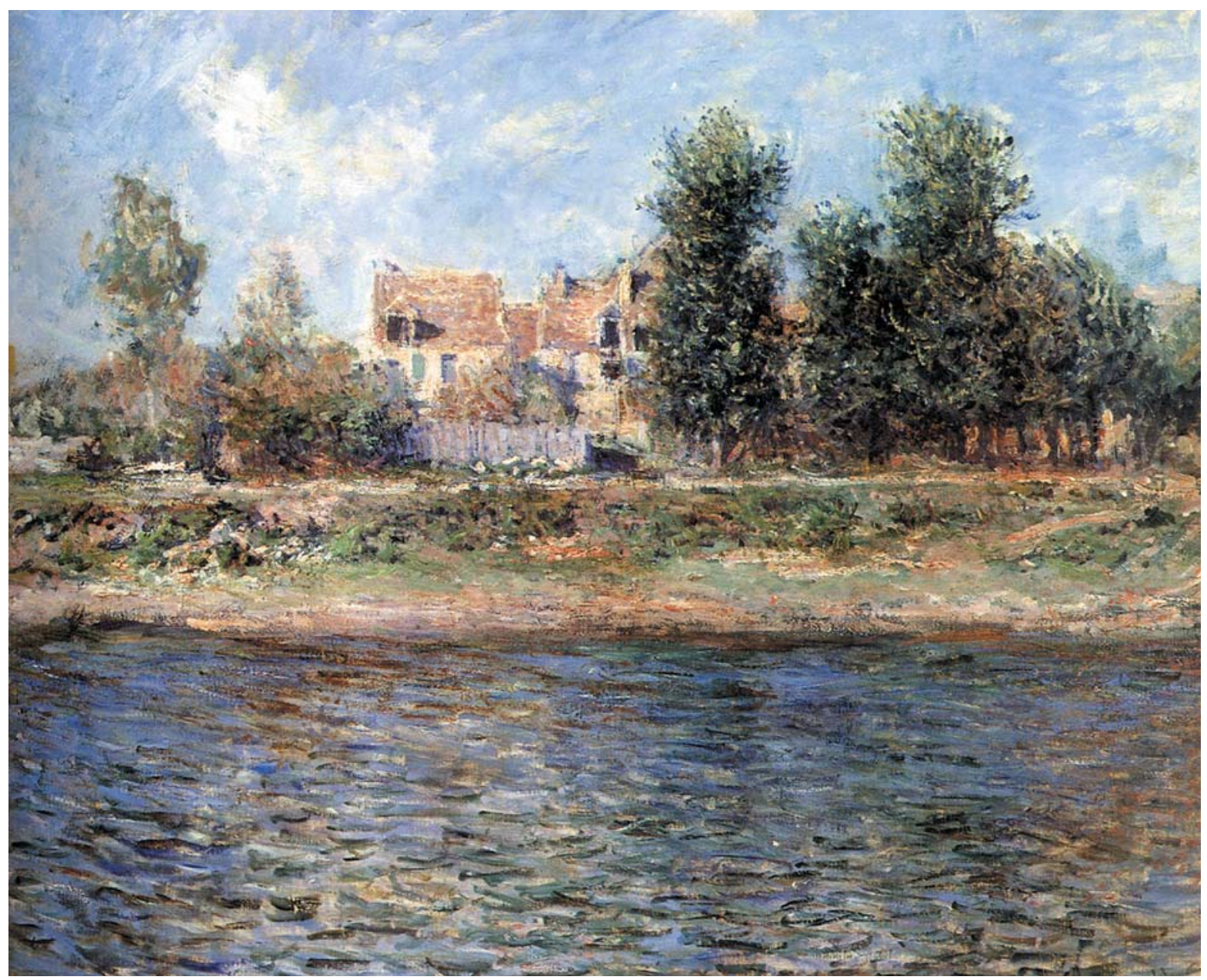

Figura 12 - Claude Monet, Orillas del Sena en Vetheuil, óleo sobre tela, $60 \mathrm{~cm} \times 72 \mathrm{~cm}$. Adquirida en la Exposición Internacional de Arte del Centenario 1910, Acervo del Museo Nacional de Bellas Artes de Buenos Aires (MNBA).

evidentemente no tenían aún la legitimidad suficiente para ser consideradas como expresiones dignas de ser coleccionadas.

Luego de insalvables diferencias con la CNBA, que acusaba a Schiaffino, entre otras cosas, de no haber presentado un inventario completo del patrimonio y de tener su residencia dentro del museo, el primer director es exonerado en septiembre de 1910. En las gestiones posteriores, el coleccionismo privado continuará funcionando como el gran alimentador del acervo, mientras que la instalación del Salón Nacional de Arte, en 1911 , va a favorecer también la incorporación de las obras premiadas de arte argentino.

Al igual que Schiaffino, los directores que lo siguieron debieron luchar constantemente con las escasas partidas presupuestarias que - en paralelo con las distintas crisis económicas y políticas del país - condicionaron directamente las posibilidades de crecimiento de la institución. Así sucede en 1914, bajo la 


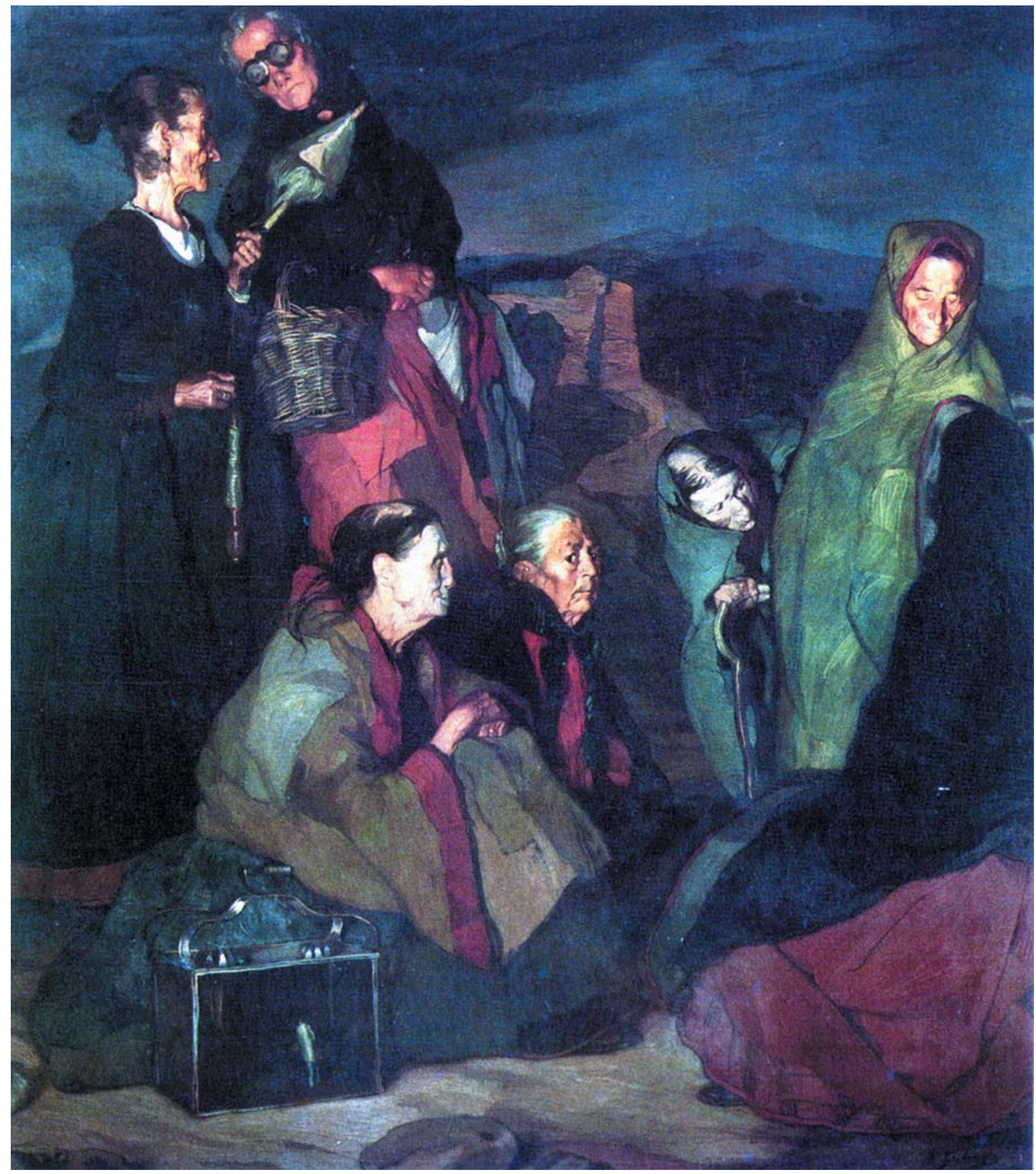

Figura 13 - Ignacio Zuloaga, Las brujas de San Millán, 1907, óleo sobre tela, 190cm × 204cm. Adquirida en la Exposición Internacional de Arte del Centenario 1910, Acervo del Museo Nacional de Bellas Artes de Buenos Aires (MNBA). 


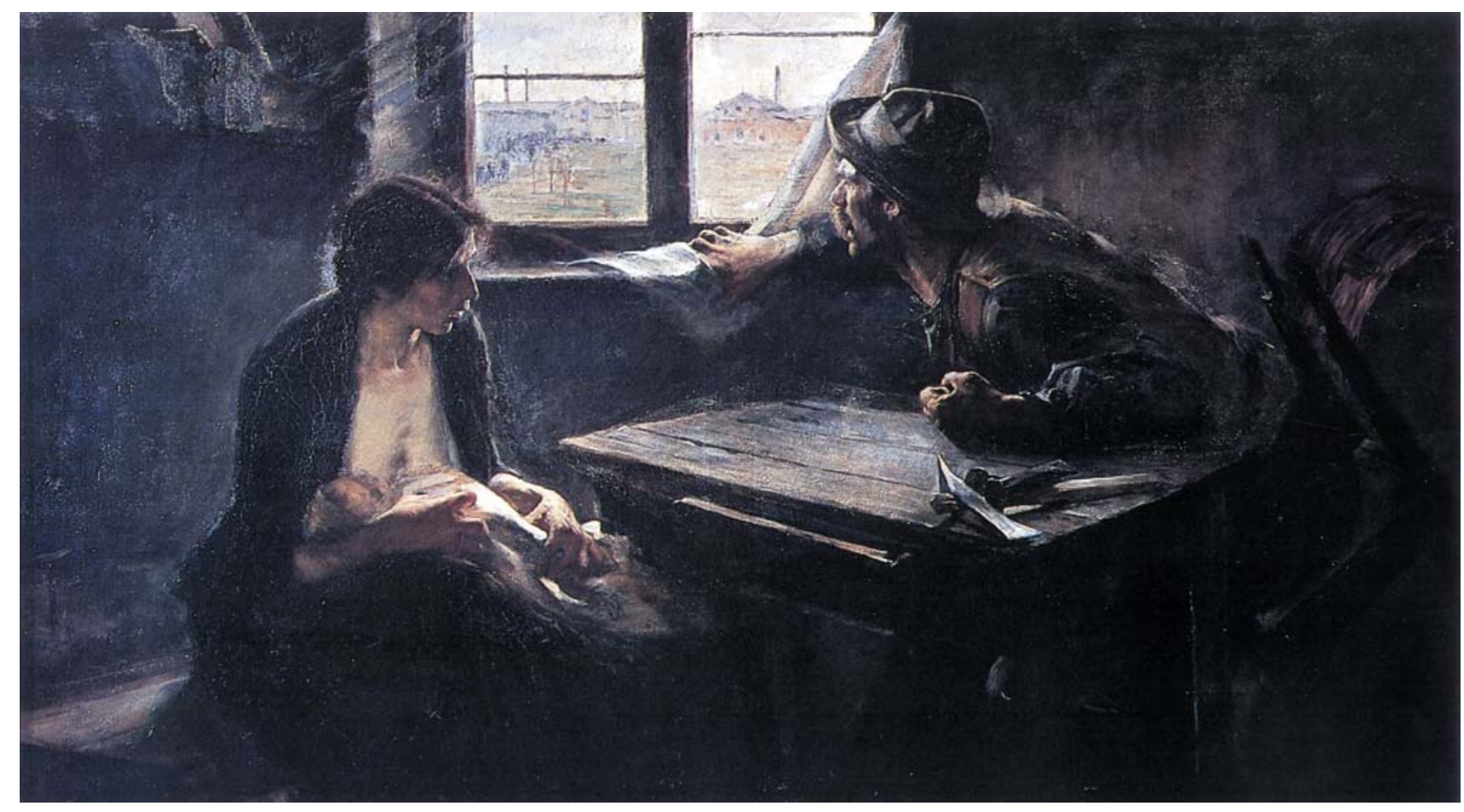

Figura 14 - Ernesto de la Cárcova, Sin pan y sin trabajo, 1892-1893, óleo sobre tela, 125,5cm x $216 \mathrm{~cm}$. Adquirido al artista en 1900, Acervo del Museo Nacional de Bellas Artes de Buenos Aires (MNBA).

dirección de Cupertino del Campo, cuando ante la inminencia de la primera guerra se postula un "acuerdo de economías" que reduce a la mitad la remesa para las adquisiciones, partida que no se restituye inmediatamente cuando los tiempos se estabilizan y se revisan muchos de los presupuestos reducidos. La ampliación del patrimonio seguirá teniendo entonces un desarrollo coyuntural que dependerá de oportunidades puntuales - ventas, donaciones, premios, legados - y no de una política estatal planteada y orientada al engrandecimiento de la institución.

El camino hacia la institucionalización artística

En las administraciones subsiguientes, el MNBA continuó siendo altamente receptivo a las donaciones de los coleccionistas privados. Así en 1912, ya con Del Campo como director, ingresarán en donación 109 cuadros, principalmente de arte francés, de manos de Carlos Madariaga y Josefa Anchorena. En el conjunto figuraban varios artistas célebres como Courbet o Fantin-Latour junto a aquella pléyade de pintores descendientes tanto del simbolismo como de la academia a los que el mercado de Buenos Aires estaba 
24. El médico y escritor Atilio Chiappori asume como secretario del MNBA en 1911 y ocupa este cargo hasta su nombramiento como director en 1931. Dirige el Museo hasta 1939 . Sobre la revista, cf. LEBRERO, 2002, p. 59-79

25. CHIAPPORI, Atilio. Donación Madariaga-Anchorena. Pallas, Buenos Aires, n. 6, 1913, p. 130 138.

26. SIBELIUS, Marco. La donación Furt: enriquecimiento del Museo Nacional. Augusta: revista de arte, Buenos Aires, a. 3, v 4, n. 23 , abril de 1920 , p. $150-183$

27. CHIAPPORI, 1946, p 172 más que habituado, como Etienne Dinet, Caro-Delvaille, Charles Cottet y Paul Chabas. Denostada por parte de la crítica de aquel momento, el entonces secretario y futuro director del MNBA - Atilio Chiappori - se ocupó de defender la colección, desde las páginas de la revista Pallas, que editó entre 1912 y 1913, donde las actividades del MNBA y el coleccionismo contemporáneo tenían un sitio destacado ${ }^{24}$. Alli Chiappori señalaba que los Madariaga-Anchorena habían apuntado precisamente a completar las escuelas ya representadas en el Museo de Bellas $\mathrm{Artes}^{25}$. Sin hacerlo en forma explícita, se recuperaba así la práctica que habían instaurado algunos coleccionistas anteriores, como Sosa y Roverano. Y nuevamente se ponía en discusión la función del MNBA, que para Chiappori debía ser representativo de todas las escuelas y tendencias que se sucedieron en la historia del arte, aún a costa de alojar obras cuestionadas o de segundo orden.

En 1920 ocurrirá algo similar con la inclusión de las 90 obras de la colección de Emilio Furt, que se caracterizaban principalmente por provenir de la Francia del siglo XIX, con ejemplares de Corot, Díaz de la Peña, Courbet, Thédore Rousseau, William Bouguereau y Henri Harpignies junto a otros artistas europeos activos hacia el fin de siglo como el italiano Filippo Cárcano o los holandeses Gustave Flasschoen y Fritz Thaulow. La donación también permitió el ingreso de pequeñas piezas de artistas centrales del siglo XIX como Delacroix y Millet (Figura 15) que, al igual que sucediera con la donación Madariaga, llevó a la crítica a justificar el mérito relativo de estos pequeños bocetos para celebrar la presencia de los nombres célebres en el periférico museo ${ }^{26}$.

Si bien ya para 1920 no era posible considerar a esta selección como estrictamente contemporánea en la medida que incluía obras realizadas hacía varias décadas o que no se correspondían con el derrotero seguido por las nuevas tendencias artísticas del siglo XX, sí es importante señalar cómo la impronta trazada por el primer coleccionismo siguió repitiéndose en estas donaciones posteriores.

Presentida en el siglo XIX y reafirmada durante el devenir del nuevo siglo, el MNBA afronta su incapacidad de pujar en el mercado internacional en pos de la adquisición de grandes piezas de arte del pasado, consolidando y asumiendo su rol como museo "moderno" tal como lo define Atilio Chiappori hacia los fines de su gestión ${ }^{27}$.

Si bien el MNBA debe reaccionar ahora ante una gran cantidad de arte argentino que empieza a circular por salones y galerías, durante la década de 1930 el arte francés decimonónico siguió gozando del favoritismo de gran parte del coleccionismo local y permaneció con un sitio de privilegio en el relato museístico de la institución. Prueba de esto son las exposiciones Escuela Francesa siglos XIX y XX y Rodin, celebradas en 1933 y 1934 por la Asociación Amigos del MNBA, entidad formada casi íntegramente por coleccionistas privados que utilizaban este espacio oficial para dar a conocer sus acervos particulares. 


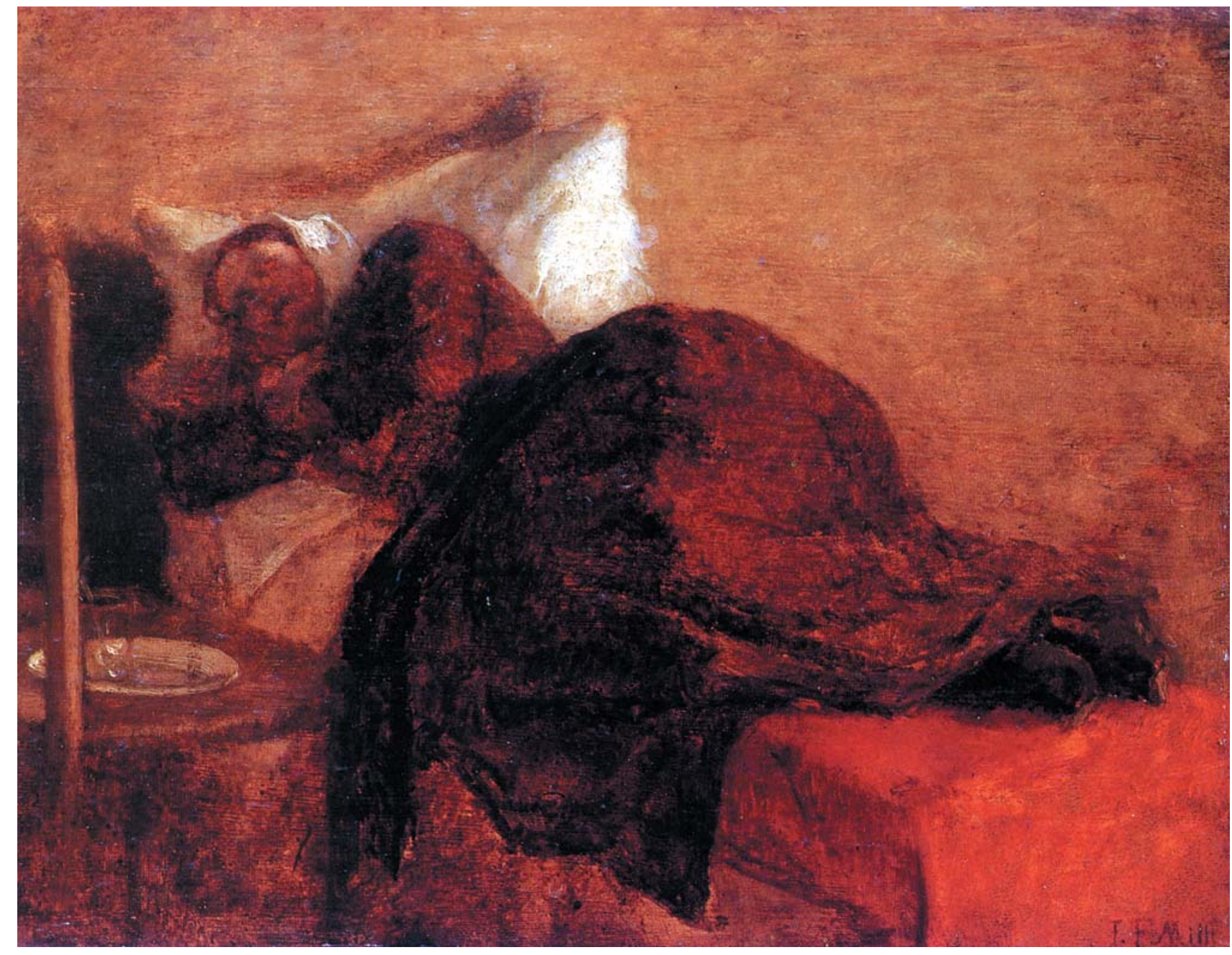

Figura 15 - Jean François Millet, La esposa del autor, óleo sobre tela, 27,5cm × 35,5cm. Donación Emilio P. Furt, Acervo del Museo Nacional de Bellas Artes de Buenos Aires (MNBA).

Las décadas de 1910 y 1920 presencian también la apertura de varios museos en el interior del país, todos ellos fundados en mayor o menor 28. Cf. PANZETTA, 2005, p. $7-15$ medida en base a donaciones particulares. Este fue el caso del ya aludido Museo Provincial de Bellas Artes de La Plata (1922), pero será también el del Museo Provincial de Bellas Artes de Córdoba. Creado en 1914 como dependencia de un museo mayormente dedicado a la historia de la ciudad, y con edificio propio y exclusivo para sus colecciones artísticas desde 1916, la institución apuntó expresamente, según señalaba su primer director Deodoro Roca, a las adquisiciones de arte moderno, privilegiando el producido en la región ${ }^{28}$.

También en la provincia de Santa Fe, el Museo Municipal de Bellas Artes de Rosario abrió sus puertas en 1920. Mucho tuvo que ver en este 
29. Cf. LA OBRA cultural de "El Círculo": 1912 1921. Rosario.

30. En 1937, el museo reabrirá en su nueva sede bajo el nombre de "Museo de Bellas Artes Juan B. Castagnino". La madre de Castagnino hizo cons truir el edificio y lo donó en nombre de su hijo Juan Bautista.

31. CONSTANTIN, 1999 , p. 161-169.

32. En 1932, el MNBA se traslada a la antigua casa de Bombas de la Ciudad sobre la Avenida del Libertador reformada $y$ adaptada para el nuevo destino, sede que ocupa hasta la actualidad. emprendimiento el espíritu de la agrupación "El Círculo", que desde 1912 nucleaba a la elite rosarina preocupada por el fomento de la cultura local. Durante su intensa actividad "El Círculo" organizó conciertos, conferencias, exposiciones y el primer salón de bellas artes concretado en 1913, que se instituye como Salón de Otoño en 1917. Son sus integrantes quienes, en forma individual o conjunta, contribuyen al permanente crecimiento del patrimonio del museo, mediante constantes donaciones principalmente de arte argentino ${ }^{29}$. En 1926, un año después de la muerte de Juan. B. Castagnino - miembro conspicuo de este grupo - entran como legado veintitrés obras de su colección de pintura argentina. Gracias a esta donación el organismo contó con la presencia de artistas ya altamente reconocidos para los años 1920 como Fernando Fader, Alfredo Guido, Italo Botti y Martín Malharro entre otros ${ }^{30}$.

En la capital de la Provincia de Santa Fe, el Museo "Rosa Galisteo de Rodríguez" fue inaugurado en 1922 sobre la donación fundadora de Martín Rodríguez Galisteo realizada dos años antes, quien cede un edificio y una biblioteca con el destino específico de alojar un museo de arte. Además de donar ocho obras de arte europeo, Martín Rodríguez sugiere la asignación de una partida de dinero para la compra de arte argentino ${ }^{31}$.

Cada una de las historias de estas instituciones, propone un perfil que - desde su nacimiento - las diferencia del modelo canónico estipulado por el MNBA, al tornarlas más permeables al arte argentino del momento, hecho fomentado por la apertura de los salones provinciales y regionales de bellas artes. Además, tanto el Museo Provincial de Córdoba como el Galisteo de Rodríguez fueron albergados tempranamente en edificios construidos ex-profeso para funcionar como museos de arte, destino que el Museo de Rosario alcanzará con su nueva sede de 1937. Esto nunca sucedió en el caso porteño, cuyo MNBA careció siempre de un edificio pensado explícitamente para ese fin ${ }^{32}$.

Este fue, sin embargo, un proyecto inalterable desde la creación del MNBA, estando muy cerca de concretarse en dos ocasiones: en 1908, durante la administración de Schiaffino, en que el arquitecto belga activo en Buenos Aires Jules Dormal presenta, a pedido del Senado, un imponente proyecto de palacio neoclásico destinado a alojar tanto el museo como la Academia Nacional de Bellas Artes. Y en 1928, bajo la dirección de Del Campo, cuando tras un concurso sale vencedor el proyecto de los arquitectos Herrera Mac Lean y Quartino Herrera para construir el nuevo museo en el Parque del Retiro. A pesar de contar con los fondos necesarios, ninguno de estos dos proyectos llegó a cumplirse efectivamente. 
Las grandes obras de arte europeo decimonónico - principalmente francés y español - que abundaron en las galerías comerciales de Buenos Aires durante las primeras décadas del siglo XX se hicieron más escasas a medida que el mercado europeo se recomponía con posterioridad a la Guerra. Al mismo tiempo, eran otros los referentes de los nuevos relatos construidos por la crítica y la historia del arte. Este arte nuevo, no sólo el de las vanguardias y el abstracto, sino también el de los nuevos realismos, apuntó su oferta hacia otros mercados que evidentemente sobrepasaron la capacidad de absorción de una plaza que, en comparación con destinos como los Estados Unidos, se presentaba día a día como más marginal.

Sin embargo, algunas de estas obras, generalmente las más templadas, arribaron al mercado argentino, acompañadas también por epígonos del arte decimonónico que continuaba afluyendo. Es decir, no es posible señalar un corte abrupto pero sí un cambio de paradigma, artístico y también económico, que poco a poco desplaza y cuestiona la novedad y necesidad de importación del arte realista, impresionista, simbolista y sus derivados.

Por otra parte, la constitución de nuevos espacios de exhibición, salones y grupos de artistas argentinos ponía en otra situación al coleccionismo local al dotar de alta visibilidad y ofrecer al mercado una inmensa cantidad de obra de autores argentinos.

No faltarán quienes, marcando la nueva tendencia, configuren un tipo distinto de coleccionismo, ya sea más propenso a las nuevas búsquedas plásticas como por ejemplo la Escuela de París, el llamado Retorno al Orden o las figuraciones de nuevo cuño de la pintura europea, o el caso de aquellos coleccionistas que se plantearon explícitamente la formación de corpus de arte argentino. Este proceso, además de ser parte de otra historia, se despega paulatinamente del patrón marcado por el primer coleccionismo, aquel que veía a Europa como meca exclusiva hacia donde se debían dirigir los artistas argentinos en formación y única productora válida de obras dignas de ser coleccionadas.

\section{REFERENCIAS}

AAVV. Museo Histórico Nacional. Buenos Aires: Manrique Zago, 1997.

AMIGO, R. El breve resplandor de la cultura del bazar. En:AAVV. Segundas jornadas: estudios e investigaciones en artes visuales y música. Buenos Aires: Instituto de Teoría e Historia del Arte "Julio E. Payró", 1998, p. 139-148.

ARTUNDO, P.(Org.). El arte francés en la Argentina: 1890-1950. Buenos Aires: Espigas, 2004. 
BALDASARRE, M. I. Los dueños del arte: coleccionismo y consumo cultural en Buenos Aires. Buenos Aires: Edhasa, 2006.

. Terreno de debate y mercado para el arte español contemporáneo: Buenos Aires en los inicios del siglo XX. En:AZNAR,Y;;WECHSLER, D. (Comp.). La memoria compartida: España y la Argentina en la construcción de un imaginario cultural (1898-1950). Buenos Aires: Paidós, 2005, p. 107-132.

CHIAPPORI,A. Luz en el templo. Buenos Aires: Ministerio de Justicia e Instrucción Pública, 1946.

CONSTANTIN, M.T. El hombre propone... y la época dispone: o cómo se dibujó el perfil del Museo Rosa Galisteo de Rodríguez. En:AAVV. Epílogos y prólogos para un fin de siglo. Buenos Aires: CAIA, 1999, p. 161-169.

FARINA, F. El museo Castagnino. En: AAVV. Un patrimonio protegido: restauración de obras maestras del museo Juan B. Castagnino de Rosario. Buenos Aires: Fundación Antorchas, 2003, p. 11-19.

GEORGEL, C. (Dir.). La jeunesse des musées: les musées de France au XIXe siècle. Paris: Editions de la Réunion des Musées Nationaux, 1994.

LEBRERO, Cecilia. Pallas (1912-1913): una revista de artes plásticas. En: SAAVEDRA, M. I.; ARTUNDO, P. (Dir.). Leer las artes: las artes plásticas en ocho revistas culturales argentinas (1878-1951). Buenos Aires: Instituto de Teoría e Historia del Arte "Julio E. Payró”, 2002, p. 59-79 (Monográfica, 6).

MALOSETTI COSTA, L. Los primeros modernos: arte y sociedad en Buenos Aires a fines del siglo XIX. Buenos Aires: Fondo de Cultura Económica, 2001.

MNBA. Obras espuestas en Museo Nacional de Bellas Artes: Catálogo. Buenos Aires, 1896.

MONTINI, P. De Génova a Rosario: la primera etapa de la colección artística de Juan B. Castagnino, Rosario 1907-1916. En: X Jornadas Interescuelas/Departamentos de Historia: ponencia. 20 al 23 de septiembre de 2005, Rosario.

PANZETTA, M. La creación del Museo Caraffa en el proyecto modernizador de Córdoba. Teórica: teoría, crítica e historia del arte contemporáneo. Córdoba, n. 1, sept. 2005, p. 7-15.

PASTOR OBLIGADO. La tertulia Guerrico: tradiciones argentinas. Barcelona: Montaner y Simon, 1903.

PROYECTO Nacional de Bellas Artes para la ciudad de Buenos Aires por Juan Benito Sosa presentado al Ministerio de Instrucción Pública en noviembre de 1886. Buenos Aires; La Plata: Imprenta, litografía y encuadernación de J. Peuser, 1889.

SAAVEDRA, M. I.;ARTUNDO, P. (dir.) Leer las artes. Las artes plásticas en ocho revistas culturales argentinas (1878-1951). Buenos Aires: Instituto de Teoría e Historia del Arte "Julio E. Payró", 2002 (Monográfica, 6). 
TELESCA,A.M.; BURUCÚA, J. E. Schiaffino corresponsal de El Diario en Europa. La lucha por la modernidad en la palabra y la imagen. Anales del Instituto de arte americano e investigaciones estéticas "Mario J. Buschiazzo", n. 27-28, 1989-1991, p. 65-73.

TRELLES, Manuel Ricardo. Memoria presentada a la Asociación de Amigos de la Historia Natural del Plata, sobre el estado del Museo y demás relativos a la institución por el Secretario de la misma, D. Manuel Ricardo Trelles. Buenos Aires: Impr. El Orden, 1856.

WECHSLER, D. Un registro moderno del arte en Córdoba. En: CAPARDI, D. (Cur.) 100 años de plástica en Córdoba, 1904-2004. Córdoba: Museo Caraffa, 2004, p. 116-125.

Artigo apresentado em 04/2006. Aprovado em 05/2006. 